\title{
A eficácia do pork barrel: a importância de emendas orçamentárias e prefeitos aliados na eleição de deputados
}

\author{
Alexandre Lima Baião \\ Cláudio Gonçalves Couto
}

\section{Introdução}

Pesquisas de opinião junto a eleitores e deputados sugerem que garantir repasses financeiros para os redutos eleitorais é um imperativo da sobrevivência política no Brasil (Ames, Baker e Rennó, 2008; Lemos e Ricci, 2011). A mídia e a academia, por sua vez, frequentemente desenvolvem suas análises assumindo que essa premissa seja verdadeira. Acontecimentos recentes, como a aprovação da Emenda Constitucional 86/2015, reforçam essa visão, uma vez que deputados e senadores se uniram para aprovar, por maioria qualificada, uma norma que garante e protege a execução de suas emendas individuais. Assim, consolidou-se a crença de que deputados tendem a promover sua reputação pessoal em bases locais específicas, alimentando o apoio de eleitores e aliados políticos por meio de emendas parlamentares e outros benefícios particularizados (Bezerra, 2001).

Tendo em vista esse quadro, seria de esperar que os estudos empíricos levassem a uma visão inequívoca de que as emendas orçamentárias têm efeito eleitoral relevante. Este, no entanto, está longe de ser o estado da arte nas pesquisas que investigaram o tema. Ao explorar o impacto eleitoral das emendas parlamentares, há tanto trabalhos que encontraram efeito positivo (Ames, 1995a; Pereira e Rennó, 2007; Firpo, Ponczek e Sanfelice, 2015) quanto estudos que identificaram efeito nulo (Samuels, 2002) ou até mesmo negativo (Mesquita, 2008).

Este artigo busca retomar o tema, lançando mão de dados e métodos mais acurados para verificar a eficácia eleitoral das emendas. Nesse sentido, propõe uma correção na forma de operacionalizar a variável pork barrel no Brasil, tendo em vista que algumas limitações técnicas da contabilidade pública dificultam associar o parlamentar à execução orçamentária de suas emendas. Adicionalmente, além de analisar o efeito agregado de todos os tipos de emendas, como fora feito em trabalhos anteriores, este artigo realiza um esforço inédito de discriminar as emendas segundo a modalidade de aplicação.

A ideia por trás da separação das emendas em função da natureza do gasto é verificar quais atores políticos, como prefeitos e dirigentes de ONGs, medeiam a relação entre deputados e eleitores. Em um sistema eleitoral em que os distritos têm elevada 
magnitude, como no Brasil, vários deputados disputam votos na mesma região. Consequentemente, conforme o argumento seminal de Lancaster (1986), o uso de pork barrel projects seria menos atrativo nesses casos, pois um parlamentar poderia se aproveitar politicamente da benfeitoria realizada por outro. A aliança com atores locais, no entanto, poderia representar uma forma de contornar o problema do credit claiming.

A descentralização política pós-1988 dotou municípios de maiores competências administrativas, políticas e legislativas, aumentando a relevância dos prefeitos no sistema político. Não por acaso, pesquisadores identificaram várias evidências de articulação partidária entre prefeitos e deputados nas eleições nacionais (Ames, 1994; Bezerra, 2001; Carneiro e Almeida, 2008; Avelino, Biderman e Barone, 2012; Graça e Souza, 2014). Além do mais, municípios são entes federativos autônomos que se relacionam diretamente com a União e recebem a responsabilidade pela execução da maioria das emendas individuais. Todos esses fatores indicam que, dentre os atores locais, os prefeitos seriam aqueles com maior potencial para auxiliar o deputado a reclamar o crédito pelas suas emendas.

Dessa forma, este artigo testa a hipótese de que as emendas executadas por meio de transferências diretas às prefeituras sejam aquelas determinantes para o sucesso eleitoral do deputado. Esses recursos satisfariam a sede de prefeitos por recursos da União e garantiriam ao deputado um importante aliado nas eleições nacionais. Além do mais, buscamos verificar aqui se essa aliança entre prefeitos e deputados, no contexto das emendas, tem cunho partidário. Mais especificamente, verifica-se até que ponto o aproveitamento político das emendas se torna mais fácil quando um dado prefeito é do mesmo partido que o deputado responsável pelos recursos alocados naquele município.

Este artigo é organizado em seis tópicos: "Introdução"; "Instituições eleitorais e pork barrel no Brasil", uma breve revisão da literatura sobre o tema; "Hipóteses"; "Dados e métodos"; "Resultados"; e, por fim, "Considerações finais".

A seção "Dados e métodos" apresenta dois subtópicos, nos quais são descritos o tratamento conferido aos dados sobre execução orçamentária das emendas e o desenho utilizado para testar a hipótese 4.

A seção "Resultados", por sua vez, está dividida em três partes. Na primeira, intitulada "O efeito eleitoral das emendas", os testes das três primeiras hipóteses são apresentados em conjunto, uma vez que derivam de regressões do resultado eleitoral contra suas emendas e outras variáveis de controle. Na segunda parte dos resultados, com o subtítulo "A alocação das emendas pelos partidos", apresenta-se o teste da hipótese 4, em que foi aplicada uma regressão descontínua para verificar o efeito do partido do prefeito na decisão que deputados tomam ao alocar suas emendas entre os diferentes municípios de seu estado. Na terceira parte, por fim, é apresentado um quadro com a "Síntese dos resultados empíricos e contribuições" teóricas do artigo. 


\section{Instituições eleitorais e pork barrel no Brasil}

Os primeiros cientistas políticos a se debruçarem sobre a democracia brasileira no período posterior aos 21 anos de regime militar se concentraram em analisar quais consequências seriam esperadas tendo em vista as regras constitucionais e eleitorais do novo sistema político (Abranches, 1988; Ames, 2001; Mainwaring, 2001). Em face de uma federação presidencialista com sistema eleitoral proporcional de lista aberta, estes trabalhos produziram deduções pessimistas sobre o funcionamento democrático do Brasil, indo desde o risco do presidencialismo multipartidário (Linz, 1994; Mainwaring, 1993a, 1993b) até o elevado estímulo ao paroquialismo e individualismo parlamentares (Ames, 1995a, 1995b, 2001; Mainwaring, 1993a, 1993b, 2001).

Boa parte das análises realizadas nesse período se basearam na ideia clássica de Carey e Shugart (1995), segundo a qual os distritos grandes e a lista aberta favoreceriam o voto pessoal. Essas características tornariam o Brasil um caso extremo de sistema candidate-centered, em que a elevada competição intrapartidária estimularia deputados a fortalecer suas reputações pessoais em detrimento dos objetivos do partido.

Desde então, vários estudos buscaram investigar a possível presença do voto pessoal no Brasil, entendido como o voto determinado por qualidades pessoais e pelo desempenho individual do candidato (Cain, Farejohn e Fiorina, 1987). Pesquisas de opinião identificaram que o eleitor, em suas decisões de voto, atribui importância muito maior ao candidato do que ao partido ao qual ele pertence (Nicolau, 2006; Ames, Baker e Rennó, 2008; Ames, Pereira e Rennó, 2011). Os deputados, por sua vez, ao serem perguntados sobre a importância eleitoral do partido vis-à-vis a importância de seu desempenho pessoal, atribuem um peso muito maior a este último (Lemos e Ricci, 2011). Em suma, na percepção tanto dos deputados quanto dos eleitores, o partido tem importância reduzida no resultado eleitoral, enquanto a reputação pessoal do candidato emerge como o fator fundamental para o sucesso nas urnas.

No Brasil, as discussões sobre voto pessoal sempre estiveram associadas às políticas de pork barrel - expressão utilizada na literatura internacional para designar o particularismo legislativo, em que deputados utilizariam políticas distributivas (Lowi, 1964) visando ao voto dos beneficiários. Esses projetos particularizados são superestimados pelo eleitor favorecido, uma vez que ele usufrui integralmente dos benefícios sem pagar a totalidade do custo. Essa característica poderia levar à alocação inadequada dos recursos públicos, fazendo com que muitos locais recebessem mais do que a distribuição racional dos recursos justificaria (Pennock, 1970).

A forma como os fatores institucionais de um sistema político determinam a presença e a intensidade das pork barrel politics não foi tão discutida nem propalada na ciência política comparada quanto ocorreu com o voto pessoal. Dessa forma, se por um lado é pacífico que as instituições eleitorais brasileiras incentivariam a competição 
intrapartidária, e consequentemente, o voto pessoal, por outro, não é possível traçar essa mesma conclusão para as pork barrel politics.

A busca pelo voto pessoal poderia estimular a prática do pork barrel, mas a magnitude dos distritos brasileiros deveria significar um empecilho ao uso dessas práticas eleitorais. O argumento clássico de Lancaster (1986) é de que sistemas nos quais vários parlamentares concorrem na mesma região desestimulariam o uso do pork barrel. Nesses sistemas seria possível o free riding (Olson, 1965), com um deputado se aproveitando dos créditos gerados pelo benefício enviado por outro parlamentar. A possibilidade de um deputado usurpar o prestígio de outro anularia os incentivos ao uso político dos projetos de pork barrel, mesmo em situações nas quais o voto pessoal fosse decisivo.

Ames (1995a; 1995b; 2001) não aplica o argumento teórico de Lancaster ao Brasil porque, para aquele autor, mesmo dentro dos grandes distritos eleitorais brasileiros os deputados cultivariam relações pessoais com determinadas localidades e erigiriam barreiras à entrada de políticos rivais. Essa situação levaria à formação de distritos informais, em que cada deputado focalizaria uma base local específica para entregar benefícios e colher votos.

Ocorre que a tese dos distritos informais foi rechaçada por estudos posteriores (Kinzo, Martins e Borin, 2004; Silva, 2009, 2013), os quais mostraram que a distribuição espacial dos votos de um deputado muda bastante de uma eleição para outra, indicando que os parlamentares não são capazes de criar barreiras à entrada de deputados rivais em suas regiões de maior votação. Dessa forma, a influência local de um deputado não é estável ao longo do tempo a ponto de ser possível falar em dominância ou em distritos informais.

Portanto, caso o pork barrel seja realmente uma peça importante do sistema político brasileiro, ainda resta saber como os parlamentares conseguiriam reclamar crédito pelos serviços prestados às suas bases eleitorais.

Além da possível dificuldade na reclamação de crédito, a utilização do pork barrel no Brasil encontra limitações legais. Conforme destacado por Lemos (2001), a Constituição Federal cria uma série de restrições para a iniciativa e aprovação de projetos de lei que busquem destinar recursos particularizados para regiões ou grupos específicos. Os estudos que analisaram a produção legislativa corroboraram a existência dessa barreira ao particularismo legislativo, mostrando que as leis produzidas pelo Congresso não têm conteúdo predominantemente paroquial (Lemos, 2001; Ricci, 2003, Amorim e Santos, 2003).

Tendo em vista as limitações legais e constitucionais ao particularismo legislativo, a janela institucional existente para que deputados beneficiassem seus redutos eleitorais corresponderia ao dispositivo da emenda orçamentária individual. Em outras palavras, a pork barrel politics, caso realmente faça parte do sistema político brasileiro, se 
materializaria por meio das emendas ao orçamento aprovadas durante sua tramitação no Congresso.

Cada parlamentar brasileiro tem direito a propor 25 emendas $^{1}$ individuais ao orçamento. Geralmente, os deputados utilizam esse dispositivo para beneficiar seus redutos com projetos de escopo local, executados com o apoio de prefeituras ou organizações sem fins lucrativos.

A tramitação das emendas individuais no Congresso segue as previsões teóricas clássicas sobre as políticas distributivas, produzindo pouco conflito entre os atores (Lowi, 1964) e sendo aprovadas por coalizões quase unânimes (Weingast, 1994). Assim, os parlamentares brasileiros aprovam praticamente todas as suas emendas, excetuando-se apenas aquelas com falhas técnicas graves (Figueiredo e Limongi, 2008; Mello, 2012). As normas de universalismo, portanto, garantem que todo deputado tenha a oportunidade de ter seus projetos inscritos na lei orçamentária, ainda que o governo possa optar por não os executar posteriormente ${ }^{2}$.

Vários autores buscaram estudar as emendas parlamentares, seja através da percepção de políticos e eleitores (Ames, Baker e Rennó, 2008; Ames, Pereira e Rennó, 2011; Lemos e Ricci, 2011), seja através dos efeitos empíricos das emendas no desempenho eleitoral (Ames, 1995a; Samuels, 2002; Pereira e Rennó, 2003, 2007; Mesquita, 2008; Sanfelice, 2010) e no comportamento parlamentar (Pereira e Mueller, 2002; Pereira e Mueller, 2004; Figueiredo e Limongi, 2002; Limongi e Figueiredo, 2005).

Do ponto de vista do eleitor, a pesquisa de opinião conduzida por Ames, Baker e Rennó (2008) levou os autores à conclusão de que as emendas seriam um dos principais fatores a explicar a decisão de voto. Quanto aos deputados, pesquisas de opinião mostraram que os parlamentares consideram bastante importante obter a execução de emendas orçamentárias (Lemos e Ricci, 2011) para sua sobrevivência política.

Além da percepção de eleitores e deputados captada nas pesquisas de opinião, outra evidência de que as emendas seriam valorizadas pelos deputados é a luta dos congressistas pela recente aprovação da Emenda Constitucional 86 de 2015, que torna obrigatória a execução das emendas individuais. Anteriormente, o chefe do Executivo tinha discricionariedade para decidir executar ou não uma emenda parlamentar. A mudança legal aprovada pelo Congresso exige que sejam executadas todas as emendas até um limite de

\footnotetext{
${ }^{1}$ Desde 2007 está em vigor o art. 49 da Resolução nº 1/06-CN, que prevê que cada parlamentar tenha o direito de propor até 25 emendas individuais. Anteriormente eram permitidas apenas 20 emendas, conforme Resolução no 1/01-CN. Já os limites monetários têm sido estabelecidos anualmente pelos Pareceres Preliminares que antecedem a aprovação da lei orçamentária.

2 Até 2013, o Executivo tinha completa discricionariedade ao executar a parcela do orçamento atingida por emendas. Naquele ano, no entanto, foi aprovada a Lei de Diretrizes Orçamentária 2014, a qual exigiu que as emendas individuais fossem executadas até o limite mínimo de 1,2\% da Receita Corrente Líquida realizada no exercício anterior. Essa norma, portanto, disciplinou a lei orçamentária executada em 2014. Mais tarde, essa mudança foi positivada na Constituição Federal pela EC 86/2015. Assim, uma parcela das emendas individuais tem execução obrigatória atualmente.
} 
$1,2 \%$ da receita corrente líquida - valor bastante razoável comparado ao montante tradicionalmente aprovado no orçamento para esse tipo de gasto.

Paradoxalmente, os estudos empíricos recentes não apontam de forma inequívoca um efeito relevante da emenda individual nos resultados eleitorais. A depender do estudo, as emendas têm efeito nulo (Samuels, 2002), negativo (Mesquita, 2008), positivo e relevante (Ames, 1995a) ou positivo e pequeno em magnitude (Firpo, Ponczek e Sanfelice, 2015).

Além do mais, caso se aceite a ideia de que as emendas geram voto, ainda não se conhece nada sobre o mecanismo causal por trás desse fenômeno. Não resta esclarecido, por exemplo, como os deputados contornariam a dificuldade de reclamar crédito por seus recursos, tendo em vista a magnitude dos distritos brasileiros (Lancaster, 1986). Caso as emendas realmente tenham efeito eleitoral, é fundamental compreender como deputados conseguem capitalizar politicamente suas propostas de alteração do orçamento.

\section{Hipóteses}

\section{Hipótese $H 1$}

A primeira hipótese do trabalho busca averiguar o efeito eleitoral das emendas, fazendo uso de dados mais atualizados e consistentes do que os utilizados em trabalhos anteriores. Uma vez que reputações pessoais são importantes na hora do voto (Nicolau, 2006; Ames, Baker e Rennó, 2008; Ames, Pereira e Rennó, 2011) e o pork barrel é valorizado tanto por deputados quanto por eleitores nas pesquisas de opinião (Ames, Baker e Rennó, 2008; Lemos e Ricci, 2011), espera-se encontrar um efeito relevante e significante desses recursos no desempenho eleitoral. Portanto, a primeira hipótese do trabalho é a seguinte:

H1: Emendas orçamentárias individuais têm efeito no resultado eleitoral do deputado.

\section{Hipótese $\mathrm{H} 2$}

O argumento clássico de Lancaster (1986) prevê que, em sistemas eleitorais em que políticos diferentes concorrem por votos na mesma região, é possível que um parlamentar "pegue carona" no pork barrel do outro. Essa situação deveria dificultar a reclamação de crédito e desestimular a utilização das pork barrel politics no Brasil.

Por outro lado, trabalhos empíricos têm apontado a importância de atores locais na reclamação do crédito por recursos enviados por atores políticos externos ao município (Golden e Picci, 2008; Coman, 2014; Bueno, no prelo). Esses atores exerceriam a função 
de líderes locais e utilizariam sua influência para favorecer o político que enviasse benefícios à localidade.

No Brasil, muitas evidências poderiam ser elencadas para defender a tese de que os prefeitos seriam os atores ideais para auxiliar o deputado a reclamar o crédito por suas emendas. Em primeiro lugar, municípios são entes federativos autônomos que se relacionam diretamente com a União e recebem a responsabilidade pela execução da maioria das emendas individuais. Em segundo lugar, vários trabalhos indicam a existência de articulação partidária entre prefeitos e deputados. Alguns demonstraram a presença de um reverse coattail effect, no qual prefeitos contribuiriam para o sucesso eleitoral de seus colegas de partido nas eleições nacionais (Ames, 1994; Carneiro e Almeida, 2008; Avelino, Biderman e Barone, 2012). Outros mostraram que o governo central, ao realizar transferências financeiras (Bueno, no prelo), e os deputados, ao propor suas emendas individuais (Barone, 2014), tenderiam a privilegiar as prefeituras de seu partido, algo também notado - numa abordagem de antropologia política - por Bezerra (2001).

O Brasil, em particular, caracteriza-se por distritos grandes e muitos deputados competindo por votos nos mesmos locais. Dessa forma, é razoável supor que transferências que sejam executadas por atores locais, sobretudo pelo prefeito, tenham eficácia eleitoral relevante, enquanto emendas que não beneficiem esses atores sejam inócuas. O prefeito, nesse caso, atuaria mediando a relação entre deputados e eleitores locais, garantindo que o deputado aliado recebesse os créditos pelas benfeitorias realizadas. Essa tese ainda não foi testada por nenhum trabalho empírico e, portanto, corresponde à segunda hipótese deste artigo:

H2: Somente as transferências a prefeituras têm impacto no voto.

\section{Hipótese H3}

Apesar da conhecida tese sobre os partidos fracos no Brasil (Mainwaring, 1993a, 1993b; Ames, 1995a), vários trabalhos apontam níveis razoáveis de articulação intrapartidária na arena eleitoral (Carneiro e Almeida, 2008; Avelino, Biderman e Barone, 2012; Barone, 2014; Bueno, no prelo). Este artigo, portanto, supõe que a coordenação intrapartidária poderia se manifestar também na reclamação de crédito pelas emendas individuais.

Desse modo, enquanto a segunda hipótese declara a importância do prefeito enquanto aliado na reclamação de crédito, a terceira supõe que os partidos permitem construir e selar as alianças entre deputados e prefeitos. Mais especificamente, a terceira hipótese assume que o efeito eleitoral das emendas de um deputado seja maior nas prefeituras controladas pelo seu colega de partido. Essa hipótese ainda não foi explorada 
por nenhum trabalho empírico no Brasil e permite complementar a $\mathrm{H} 2$, explorando o papel, não somente de prefeitos, mas também de prefeitos copartidários:

H3: O pertencimento do prefeito ao partido do parlamentar aumenta o efeito eleitoral das emendas.

\section{Hipótese $\mathrm{H} 4$}

Se a hipótese 3 for verdadeira, deputados racionais e informados iriam priorizar as prefeituras dominadas pelo seu partido. Isso se refletiria no valor proposto pelo deputado ao alocar suas emendas e também no esforço que ele faria no sentido de garantir a execução dos recursos. Espera-se, portanto, que, quando um partido ganhe a eleição municipal para prefeito, as emendas enviadas e executadas pelos parlamentares do partido tenham um acréscimo nos anos seguintes.

Essa hipótese visa retomar uma questão já abordada por Barone (2014) e por Bueno (no prelo), com a diferença de que se incluíram, neste artigo, dados e testes adicionais para avaliar o impacto do partido na prefeitura. Desse modo, a quarta e última hipótese do trabalho é a que segue:

H4: Os deputados tendem a destinar maior volume de emendas para municípios em que o prefeito é seu colega de partido.

\section{Dados e métodos}

As três primeiras hipóteses deste artigo $(\mathrm{H} 1, \mathrm{H} 2$ e H3) foram testadas por meio de regressões com o desempenho eleitoral como variável dependente. Para tanto, utilizaramse os dados referentes a três legislaturas do Congresso Nacional: 2003-2006, 2006-2010 e 2010-2014. A amostra compreende 976 deputados federais titulares que passaram pelo Congresso Nacional durante esse período e que, portanto, tiveram oportunidades de propor emendas parlamentares individuais. A variável de interesse foi extraída da execução orçamentária das emendas parlamentares ao longo de todo esse período.

Mais especificamente, este artigo empregou a seguinte equação de votos:

$$
Y_{i j t}=\beta_{0}+\beta_{1} P_{\mathrm{ijt}}+\beta_{2} X_{\mathrm{ijt}}+\varepsilon_{\mathrm{ijt}}
$$

Em que "i" se refere ao deputado, "j" ao município, "t" ao momento da disputa eleitoral e " $\varepsilon$ " ao erro. A variável dependente " $y$ " consiste no número de votos nominais recebidos pelo deputado "i" no município "j" na disputa eleitoral "t". A matriz "P" agrupa as variáveis de pork barrel e a matriz "X," as variáveis de controle. 
Conforme mostrado no levantamento dos estudos empíricos sobre pork barrel no Brasil, cada trabalho utilizou uma especificação diferente, o que pode interferir nos resultados e conclusões. Para garantir que as conclusões não fossem sensíveis às escolhas metodológicas discricionárias do pesquisador, cada hipótese deste artigo foi testada por meio de seis especificações diferentes.

No primeiro modelo é realizada uma regressão em que a variável de interesse - o pork barrel - é o valor total empenhado. No segundo, a variável é o valor total empenhado por eleitor. No terceiro, a variável de interesse é o log do valor absoluto empenhado, enquanto a dependente é log do número de votos; ou seja, o terceiro modelo é a versão "log-log" do primeiro. Resumindo, os modelos tiveram como variável dependente e independente, respectivamente: 1 ) número de votos e valor empenhado; 2) número de votos e valor empenhado por eleitor; 3 ) log do número de votos e log do valor empenhado. Os controles, por sua vez, foram os mesmos em todos os modelos.

Cada uma dessas regressões, por sua vez, foi aplicada também em uma subamostra em que se excluíram municípios com população superior a 200 mil habitantes, dando origem a seis diferentes modelos. Parte-se do pressuposto de que conglomerar megalópoles, capitais e municípios pequenos em uma mesma análise também poderia prejudicar as conclusões, e, portanto, foram apresentados resultados para a amostra completa e para essa subamostra.

A variável dependente foi definida como número de votos do deputado nas eleições nacionais em 2006, 2010 e 2014. Como os dados estão desagregados por município, é considerado o desempenho do deputado em cada município de seu estado. Todas as regressões deste artigo utilizaram essa variável dependente, sendo que em alguns casos ela sofreu transformação logarítmica.

A variável dependente, o número de votos, é afetada por uma miríade ampla de fatores, muitos dos quais apresentam baixa disponibilidade de dados no Brasil. Por esse motivo, aqui lançamos mão de uma regressão em dados em painel com efeito-fixo para cada par deputado-município. Assim, controlam-se variáveis que não se alteram ao longo do tempo, mas que podem afetar diretamente o resultado eleitoral no município, como quando o deputado desenvolve uma reputação pessoal na Câmara dos Vereadores de certa localidade antes de ingressar no Congresso.

As seis especificações descritas acima foram aplicadas em cada umas das três hipóteses que organizam este artigo. O teste da hipótese 1 , que envolve o efeito eleitoral das emendas de forma geral, utilizou o valor total empenhado durante a legislatura do deputado. Já nos modelos que testam a hipótese 2, a variável explicativa é desagregada em função das quatro principais modalidades de aplicação utilizadas entre os parlamentares. Assim, em parte dos modelos a emenda é separada em: 1) aplicação direta da União; 2) transferências a governos estaduais; 3) transferências aos governos municipais; 4) transferências a instituições sem fins lucrativos. 
São arroladas abaixo as variáveis explicativas utilizadas neste artigo para representar os recursos de emendas:

Emendas totais - representa o volume total de emendas orçamentárias que foram empenhadas durante a legislatura do respectivo deputado no município.

Emendas - governo estadual: representa o volume total de emendas orçamentárias que foram empenhadas durante a legislatura do respectivo deputado no município, classificadas na modalidade de aplicação "transferências ao governo estadual".

Emendas - entidade privada sem fins lucrativos (Emenda - ESFL): representa o volume total de emendas orçamentárias que foram empenhadas durante a legislatura do respectivo deputado no município, classificadas na modalidade de aplicação "transferências a entidades sem fins lucrativos".

Emendas - governo federal: representa o volume total de emendas orçamentárias que foram empenhadas durante a legislatura do respectivo deputado no município, classificadas na modalidade de aplicação "aplicação direta da União".

Emendas - governo municipal: representa o volume total de emendas orçamentárias que foram empenhadas durante a legislatura do respectivo deputado no município, classificadas na modalidade de aplicação "transferência a municípios".

As variáveis de controle, por sua vez, englobam os fenômenos que têm efeito no voto e que variam ao longo do tempo em um mesmo par deputado-município. Como há efeito fixo para cada par deputado-município, os fatores que não se alteram ao longo do período para cada um desses pares se encontram controlados no modelo. Abaixo estão elencadas as variáveis de controle utilizadas:

É do partido do governador: Variável igual a 1 se o partido do deputado é o mesmo que o do governador e 0 , caso contrário.

É do partido do prefeito: Variável igual a 1 se o partido do deputado é o mesmo que o do prefeito e 0 , caso contrário.

É do partido do presidente: Variável igual a 1 se o partido do deputado é o mesmo que o do presidente e 0 , caso contrário.

Número de legislaturas: Número de legislaturas em que o deputado já exerceu mandato na Câmara dos Deputados.

Dummy_troca: Variável igual a 1 se o deputado trocou de partido nos quatro anos anteriores e 0 , caso contrário.

Para testar a hipótese 3, interagiu-se a variável de controle "é do partido do prefeito" com o valor das emendas orçamentárias. Assim, foi possível mensurar o aumento na eficácia das emendas devido à conexão intrapartidária entre deputado e prefeito. Dessa maneira, as hipóteses 1,2 e 3 foram testadas conforme os modelos apresentados no Quadro 1: 
Quadro 1

Síntese dos modelos para teste das hipóteses 1, 2 e 3

\begin{tabular}{|c|c|c|l|c|}
\hline Hipótese & Modelo & $\begin{array}{c}\text { Variável } \\
\text { dependente }\end{array}$ & Variáveis independentes & $\begin{array}{c}\text { Sinal } \\
\text { esperado }\end{array}$ \\
\hline \multirow{2}{*}{1} & \multirow{2}{*}{2} & Voto & Emendas + controles & + \\
\cline { 3 - 5 } & \multirow{2}{*}{$\begin{array}{c}\text { Regressão } \\
\text { com dados } \\
\text { em painel }\end{array}$} & Voto & $\begin{array}{l}\text { Emendas de transf. a prefeituras }+ \\
\text { outras formas de emendas }+ \\
\text { controles }\end{array}$ & + \\
\cline { 3 - 5 } 3 & \multirow{2}{*}{3} & Voto & $\begin{array}{l}\text { Emendas de transf. a prefeituras }+ \\
\text { Emendas de transf. a prefeituras } * \\
\text { Dummy de ser do mesmo partido } \\
\text { que o prefeito + outras formas de } \\
\text { emendas + controles }\end{array}$ & + \\
\hline
\end{tabular}

Fonte: Elaboração própria.

As Figuras 1 e 2 apresentam as relações causais que subjazem às três primeiras hipóteses e indicam, entre parênteses, o sinal esperado dos coeficientes nas regressões. No teste da hipótese 1, as emendas são aglutinadas sem levar em consideração a forma de gasto, assim como fora feito nos trabalhos que antecederam este artigo. Nos testes seguintes, as emendas são discriminadas em função da modalidade de aplicação e uma interação é acrescentada no modelo para captar um eventual efeito mediador do prefeito correligionário. Apresentam-se os modelos simplificado e completo nas Figuras 1 e 2, respectivamente:

Figura 1

Fatores determinantes do voto - Modelo simplificado

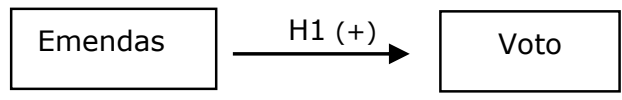

Fonte: Elaboração própria. 
Figura 2

Fatores determinantes do voto - modelo completo

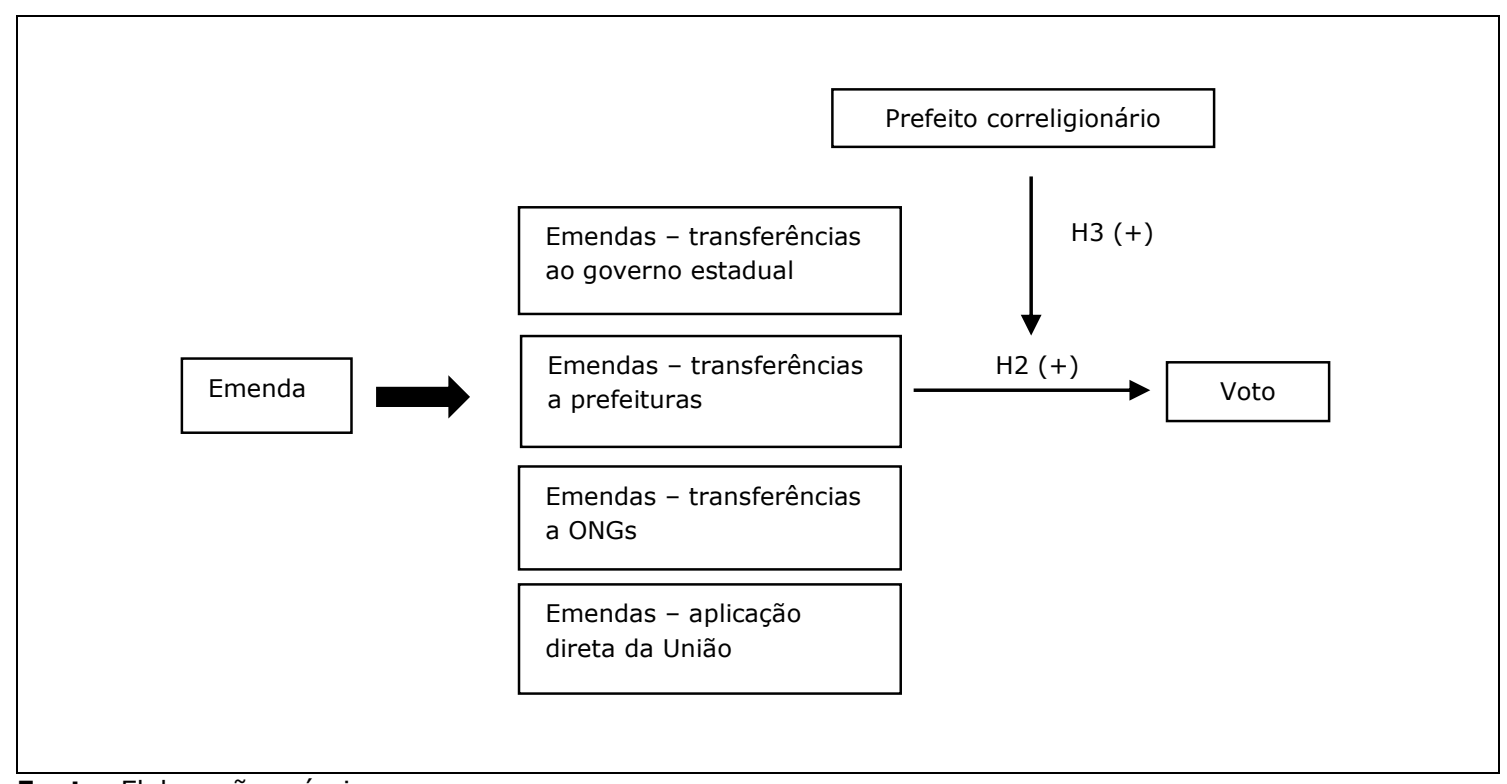

Fonte: Elaboração própria.

A variável pork barrel

A execução financeira orçamentária do governo brasileiro, conforme previsto pelas normas de direito financeiro, segue uma série de etapas que vão desde a realização da licitação até o pagamento do fornecedor. Dentre essas fases, este artigo utilizou o empenho para operacionalizar a variável pork barrel.

Em primeiro lugar, o empenho só pode ser executado no ano do orçamento que recebeu a emenda orçamentária, ao contrário da liquidação e do pagamento. Não ser possível definir o momento exato da liquidação ou do pagamento torna impossível utilizar essas variáveis numa regressão com dados em painel. Assim, o empenho é a melhor proxy disponível para captar o benefício entregue pelo deputado à região, considerando a importância de delimitar temporalmente o repasse dos recursos.

Dessa forma, a variável pork barrel deste artigo consiste no empenho das emendas individuais executadas durante o mandato do deputado. O resultado da eleição de outubro de 2006, por exemplo, é determinado pelo total de valores empenhados, referentes a suas emendas, nos exercícios financeiros de 2003, 2004, 2005 e 2006.

A operacionalização da variável pork barrel também exigiu uma adaptação dos dados disponibilizados pelo governo. Atualmente todos os dados de execução orçamentária do governo federal são obtidos por meio do Sistema Integrado de Administração Financeira 
A EFICÁCIA DO PORK BARREL

do Governo Federal (Siafi). Esse sistema permite o registro e o controle da execução do orçamento e é desenhado conforme as normas da contabilidade pública brasileira.

Ocorre que até o período abordado por este artigo, o número da emenda parlamentar não constava nos documentos de lançamento do Siafi. Assim, nenhum dos relatórios produzidos pelo sistema e utilizados pelos pesquisadores que estudaram as emendas parlamentares mostra a execução das emendas, mas tão somente a execução das programações criadas ou atingidas por elas.

Em 2014, por exemplo, quase $30 \%$ das emendas alteraram um crédito orçamentário cuja classificação funcional-programática e município beneficiário eram comuns à outra emenda. Quando mais de um deputado envia emenda para a mesma programação, o SIGA Brasil, que extrai relatórios diretamente do Siafi, na maior parte das vezes atribui toda a execução da programação a apenas um dos deputados envolvidos, enquanto as emendas dos demais aparecem erroneamente com execução nula.

Dessa forma, até o ano desta pesquisa não há, no Siafi ou na própria contabilidade pública, informação que identifique se a despesa executada deriva de uma emenda orçamentária. Uma benfeitoria pode ser construída no município com dinheiro de uma dotação na Lei Orçamentária criada pelo governo federal e ampliada com dinheiro de várias emendas. Os próprios eleitores e atores políticos locais, como prefeitos e dirigentes de ONGs, não possuem um método inequívoco de estabelecer a porção de crédito que cada um dos responsáveis mereceria. No entanto, é razoável supor que, tudo o mais constante, um deputado cuja emenda ampliou a dotação em 1 milhão de reais irá receber mais crédito do que um deputado que a estendeu em apenas 10 mil reais.

Com base nessa ideia, este artigo distribuiu a execução da programação entre os deputados na medida de suas contribuições, ou seja, na medida do valor proposto por eles em suas emendas. Esse procedimento corrigiu os dados de execução orçamentária nos casos em que duas ou mais emendas atingiram a mesma programação do orçamento.

Outra preocupação que emergiu durante esta pesquisa foi a possibilidade de a execução englobar a parcela da dotação criada pela própria União ao elaborar o orçamento. No entanto, a maioria das emendas individuais é destinada a modalidades de aplicação que descentralizam recursos para atores locais ou subnacionais, criando dotações distintas das utilizadas pelo governo federal. Além do mais, mesmo quando a emenda utiliza a modalidade de aplicação número 90 (aplicação direta da União), o deputado quase sempre especifica o município, formando uma programação única. Consequentemente, o desafio maior ao definir a execução das emendas individuais não foi separar a parcela da dotação de responsabilidade do Executivo, mas sim separar as diferentes emendas umas das outras.

Segundo o levantamento deste artigo, nenhum dos estudos anteriores levou em consideração essa limitação dos dados. Considerando o percentual elevado de emendas que afetam a mesma programação, espera-se que o método aplicado aqui - de distribuir 
a execução da programação conforme o valor proposto e aprovado pelo deputado - possa melhorar a precisão das estimativas e a confiabilidade dos resultados.

\section{Regressão descontínua}

Para testar a quarta hipótese (H4), buscou-se comparar observações nas quais a eleição foi decidida por poucos votos. A vitória de um partido na eleição para prefeito depende de forma descontínua e determinística (sharp cut-off) do número de votos dos candidatos. Consequentemente, próximo à descontinuidade há uma atribuição aleatória do tratamento, que permite testar seu efeito com grau razoável de validade interna - método conhecido como regressão descontínua (RD).

Na RD utilizada neste artigo, a unidade de observação é o partido "p", no município " $m$ ", na eleição " $t$ ". Assim, cada candidato que ganhou ou perdeu por uma diferença marginal está associado a um valor de emendas $Y_{p, m, t}$ e a uma margem de votos $X_{p, m, t}$. A $\mathrm{Y}_{\mathrm{p}, \mathrm{m}, \mathrm{t}}$ assume $\mathrm{o}$ valor de emendas individuais propostas ou empenhadas pelo partido, a depender do modelo.

A running variable $\mathrm{X}_{\mathrm{p}, \mathrm{m}, \mathrm{t}}$ foi definida como a proporção de votos do candidato mais votado menos a proporção de votos do segundo colocado no município, sendo positiva para o vencedor e negativa para o perdedor. Ou seja, a margem de vitória $X_{p, m, t}$ é simétrica para os dois primeiros colocados em um município, variando apenas em sinal. Os demais candidatos, que não ficaram nem em primeiro nem em segundo lugar, foram excluídos da análise. Dessa forma, o efeito causal do alinhamento partidário no valor das emendas pode ser definido pela seguinte equação:

$$
E\left[\mathrm{y}_{p m t}(1)-\mathrm{y}_{p m t}(0) \mid x_{p m t}=0\right]=\lim _{\epsilon \downarrow 0} \mathrm{E}\left[\mathrm{y}_{p m t} \mid x_{p m t}=\epsilon\right]-\lim _{\epsilon \uparrow 0} \mathrm{E}\left[\mathrm{y}_{p m t} \mid x_{p m t}=\epsilon\right]
$$

Há vários métodos disponíveis para estimar o efeito local expresso pela equação acima. Além de modelos de mínimos quadrados ordinários em regressões lineares e polinomiais, este artigo contou com regressões ponderadas por uma função Kernel triangular $^{3}$. As formas funcionais utilizadas em cada regressão são pormenorizadas no Apêndice 1 .

O tamanho da faixa de valores utilizados foi escolhido manualmente utilizando as margens de $10 \%$, 5\% e 2,5\%. Além destas, também foi utilizado o bandwidth ótimo de Imbens e Kalyanaraman ${ }^{4}$ (IK) (2012).

\footnotetext{
3 Trata-se de uma regressão não paramétrica em que os pesos das observações decaem suavemente à medida que elas se distanciam da descontinuidade. Este artigo segue a recomendação de Imbens e Kalyanaraman (2012) ao usar uma função Kernel triangular, segundo a qual os pesos decaem linearmente de 1 (na descontinuidade) até 0 (no ponto mais distante da bandwidth).

4 Esses autores propõem um algoritmo complexo que utiliza como parâmetros, na região próxima da descontinuidade, a variância dos resultados, a densidade da running variable e o formato das curvas nos
} 
A análise do efeito das eleições municipais nas emendas também foi realizada por Barone (2014). Contudo, no trabalho daquele autor excluiu-se o ano seguinte às eleições municipais, pois, segundo ele, "como a LOA [Lei Orçamentária Anual] deve ser aprovada até o final de agosto de cada ano e as eleições ocorrem em outubro, em t os parlamentares não sabem qual será o partido do prefeito no ano seguinte" (Barone, 2014, p. 90). Ocorre que, ao contrário do que foi considerado naquele trabalho, a LOA deve ser aprovada até o final da sessão legislativa, o que equivale ao dia 22 de dezembro para o governo federal. Assim, a maior parte das emendas são submetidas após a divulgação dos resultados eleitorais, e, portanto, não se justifica a exclusão do ano seguinte à eleição municipal. Neste artigo, portanto, optou-se por analisar todos os quatro anos seguintes à eleição.

Dessa forma, este artigo utilizou dados sobre as emendas propostas e executadas das leis orçamentárias de 2005 a 2012. A regressão descontínua, portanto, permitiu analisar o efeito da eleição majoritária de 2004 nas emendas incluídas na programação orçamentária de 2005, 2006, 2007 e 2008. O efeito da eleição de 2008, por sua vez, é associado à execução das leis orçamentárias de 2009, 2010, 2011 e 2012.

Além do mais, diferentemente do trabalho de Barone (2014), analisou-se o impacto também no empenho das emendas, e não apenas na proposição. Esse teste visa complementar a análise sobre o impacto do prefeito na eficácia eleitoral das emendas. É esperado que, caso as emendas enviadas para as prefeituras copartidárias sejam mais eficazes na busca por votos, os deputados as priorizem tanto no momento de enviar os recursos quanto na ocasião de pressionar o governo a executá-las.

A Figura 3 consolida graficamente a relação causal enunciada na hipótese 4 e o sinal esperado do coeficiente na regressão descontínua. O Quadro 2, por sua vez, sintetiza as principais informações do modelo utilizando o mesmo formato do Quadro 1, no qual se apresentaram as demais hipóteses.

lados opostos. Quanto maior a variância, menor a densidade e mais simétricos os formatos, maior é a bandwidth escolhida. 
Figura 3

Efeito do partido do prefeito na alocação das emendas entre os municípios

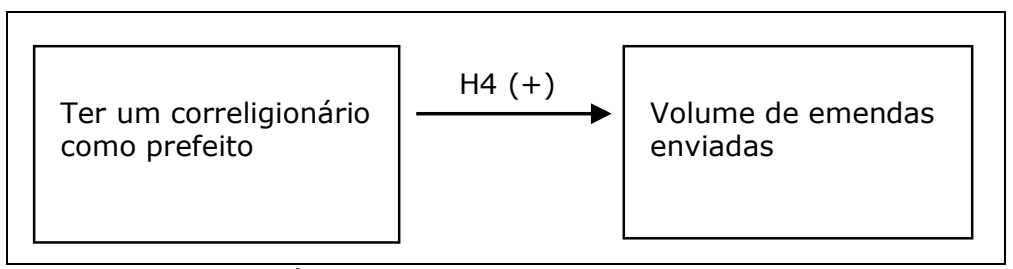

Fonte: Elaboração própria.

Quadro 2

Síntese do modelo para teste da hipótese 4

\begin{tabular}{|c|c|c|c|c|}
\hline Hipótese & Modelo & Variável dependente & $\begin{array}{c}\text { Variáveis } \\
\text { independentes }\end{array}$ & $\begin{array}{c}\text { Sinal } \\
\text { esperado }\end{array}$ \\
\hline 4 & $\begin{array}{c}\text { Regressão } \\
\text { descontínua }\end{array}$ & $\begin{array}{c}\text { Emendas enviadas* } \\
\text { (proposição e } \\
\text { empenho) }\end{array}$ & $\begin{array}{c}\text { Dummy ser do partido do } \\
\text { prefeito + controles** }\end{array}$ & + \\
\hline
\end{tabular}

Fonte: Elaboração própria.

* Volume total de emendas individuais enviadas pelos deputados do partido que disputou, na margem, a eleição municipal para prefeito.

** Esses controles consistem, nesse caso, nas diversas formas polinomiais da running variable incluídas no modelo.

\section{Resultados}

O efeito eleitoral das emendas

Ano após ano, cada deputado brasileiro inscreve milhões de reais ao orçamento por meio das emendas orçamentárias individuais. Conforme as informações apresentadas na Tabela 1, o deputado médio conseguiu obter o empenho de, aproximadamente, 5 milhões de reais entre 2011 e 2014, considerando apenas a parcela de suas emendas destinadas aos municípios na fase de proposição ${ }^{5}$. Considerando o número de eleitores de cada município atendido, os dados indicam que cada deputado distribuiu quase 58 reais por eleitor 6 .

\footnotetext{
5 Conforme já explicado anteriormente, as emendas que não especificaram um município como localidade atendida, na fase de proposição, têm a identificação de sua execução orçamentária prejudicada. Por isso, essas emendas foram excluídas da análise apresentada na Tabela 1.

6 O cálculo do valor por eleitor atendido pelo parlamentar não considerou todos os eleitores do estado, mas apenas os eleitores dos municípios atendidos pelas suas emendas individuais.
} 
Tabela 1

Valor médio empenhado pelos deputados nos estados, de 2011 a 2014

\begin{tabular}{|l|c|c|}
\hline Estado & $\begin{array}{c}\text { Valor empenhado pelos deputados } \\
\text { por eleitor atendido }\end{array}$ & $\begin{array}{c}\text { Valor médio empenhado pelos } \\
\text { parlamentares do estado }\end{array}$ \\
\hline$A C$ & $\mathrm{R} \$ 40,15$ & $\mathrm{R} \$ 10.766834,00$ \\
\hline $\mathrm{RR}$ & $\mathrm{R} \$ 48,17$ & $\mathrm{R} \$ 3.343149,00$ \\
\hline $\mathrm{AP}$ & $\mathrm{R} \$ 61,68$ & $\mathrm{R} \$ 8.131938,00$ \\
\hline $\mathrm{MG}$ & $\mathrm{R} \$ 44,81$ & $\mathrm{R} \$ 3.579272,00$ \\
\hline $\mathrm{RJ}$ & $\mathrm{R} \$ 7,76$ & $\mathrm{R} \$ 10.327674,00$ \\
\hline $\mathrm{SP}$ & $\mathrm{R} \$ 27,29$ & $\mathrm{R} \$ 5.373855,00$ \\
\hline Nacional & $\mathrm{R} \$ 57,71$ & $\mathrm{R} \$ 5.034325,00$ \\
\hline
\end{tabular}

Fonte: Elaboração própria com base nos dados do SIGA Brasil.

Observações:

Foram considerados apenas os deputados titulares.

Foram consideradas apenas as emendas com localidade municipal especificada, por ser possível rastrear sua execução orçamentária.

Valores reais de 2014.

O primeiro objetivo deste artigo é testar empiricamente o efeito eleitoral dessas emendas, lançando mão de dados mais detalhados sobre a execução orçamentária e de uma forma mais fidedigna de operacionalizar a variável pork barrel. O primeiro teste empírico busca somente avaliar o impacto geral das emendas orçamentárias individuais no voto, sem discriminá-las em função da natureza do gasto. A Tabela 2 apresenta os resultados desse teste, que indicam um impacto significativo em quatro dos seis modelos.

O terceiro modelo, por exemplo, mostra que cada 1 real por eleitor se converte em 1,75 voto para o parlamentar. Considerando que cada deputado consegue obter o empenho aproximado de 58 reais por eleitor atendido, a magnitude do coeficiente pode não ser relevante nas urnas, apesar de ser significativa estatisticamente. 0 modelo com log, por sua vez, aponta que, dobrando o dinheiro enviado para um município, o deputado consegue um incremento inferior a $3 \%$.

Adicionalmente, percebe-se que pertencer ao partido do presidente ou do prefeito garante votos, enquanto trocar de partido na última legislatura leva a uma punição nas urnas. Dentre essas variáveis, a que parece ter efeito maior é a conexão partidária com o prefeito, resultado que se coaduna com os achados de Avelino, Biderman e Barone (2012). O prefeito, portanto, favorece a eleição dos candidatos correligionários que disputam as eleições nacionais, indicando a presença de conexões intrapartidárias no sistema eleitoral brasileiro. 
Tabela 2

Efeito das emendas totais, sem discriminá-las segundo a modalidade de aplicação

\begin{tabular}{|c|c|c|c|c|c|c|}
\hline & $\begin{array}{l}\text { Modelo } \\
\text { Empenho }\end{array}$ & $\begin{array}{c}\text { Modelo } \\
\text { Empenho e } \\
\text { Pop }<200\end{array}$ & $\begin{array}{l}\text { Modelo } \\
\text { Empenho } \\
\text { por eleitor }\end{array}$ & $\begin{array}{c}\text { Modelo } \\
\text { Empenho } \\
\text { por eleitor } \\
\text { e Pop }<200\end{array}$ & $\begin{array}{l}\text { Modelo } \\
\text { Log log }\end{array}$ & $\begin{array}{l}\text { Modelo } \\
\text { Log log e } \\
\text { Pop }<200\end{array}$ \\
\hline \multirow{2}{*}{$\begin{array}{l}\text { Emendas } \\
\text { totais (H1) }\end{array}$} & 0,48 & 0,17 & 1,76 & 1,71 & 0,025 & 0,026 \\
\hline & $(1,84)$ & $(0,96)$ & $(5,18)^{* *}$ & $(5,10)^{* *}$ & $\begin{array}{c}(12,93)^{*} \\
*\end{array}$ & $(12,94)^{* *}$ \\
\hline \multirow{2}{*}{$\begin{array}{l}\text { Pertencer ao } \\
\text { partido do } \\
\text { governador }\end{array}$} & 5,86 & 8,60 & 7,06 & 9,08 & $-0,02$ & $-0,02$ \\
\hline & $(0,66)$ & $(1,03)$ & $(0,80)$ & $(1,09)$ & $(1,90)$ & $(1,88)$ \\
\hline \multirow{2}{*}{ Dummy_troca } & $-16,06$ & $-13,24$ & $-16,57$ & $-13,30$ & $-0,06$ & $\begin{array}{l}-0,065 \\
\end{array}$ \\
\hline & $(1,96)^{*}$ & $(2,35)^{*}$ & $(2,00)^{*}$ & $(2,37)^{*}$ & $(6,51)^{* *}$ & $(6,49) * *$ \\
\hline \multirow{2}{*}{$\begin{array}{l}\text { Pertencer ao } \\
\text { partido do } \\
\text { prefeito }\end{array}$} & 74,66 & 74,03 & 80,33 & 74,87 & 0,104 & 0,104 \\
\hline & $(6,36)^{* *}$ & $(9,88)^{* *}$ & $(6,53)^{* *}$ & $(10,22)^{* *}$ & $(8,51)^{* *}$ & $(8,50)^{* *}$ \\
\hline \multirow{2}{*}{$\begin{array}{l}\text { Pertencer ao } \\
\text { partido do } \\
\text { presidente }\end{array}$} & 35,88 & 31,63 & 34,79 & 31,73 & 0,175 & 0,174 \\
\hline & $(2,18)^{*}$ & $(2,08)^{*}$ & $(2,13)^{*}$ & $(2,09) *$ & $(4,20)^{* *}$ & $(4,20)^{* *}$ \\
\hline \multirow{2}{*}{$\begin{array}{l}\text { Número de } \\
\text { legislaturas }\end{array}$} & $-10,12$ & 4,53 & $-9,41$ & 4,61 & 0,074 & 0,074 \\
\hline & $(1,06)$ & $(1,06)$ & $(1,01)$ & $(1,07)$ & $(8,69) * *$ & $(8,70) * *$ \\
\hline $\mathrm{R}^{2}$ ajustado & 0,78 & 0,85 & 0,78 & 0,85 & 0,79 & 0,79 \\
\hline$F$ & 13,06 & 19,44 & 17,09 & 22,10 & 85,60 & 83,39 \\
\hline $\mathrm{N}$ & 420.105 & 419.536 & 420.105 & 419.536 & 420.105 & 419.536 \\
\hline
\end{tabular}

Fonte: Elaboração própria com base nos dados do SIGA Brasil, CEPESPData e site da Câmara dos Deputados.

Estatísticas t robustas entre parênteses.

$*$, **, *** indicam significância a 90\% 95\%, e 99\%, respectivamente.

Efeito fixo para deputado-município em todos os modelos.

Na Tabela 3, separaram-se as emendas segundo a modalidade de aplicação - um esforço inédito dentre os estudos que buscaram verificar o uso eleitoral das emendas. Ao propor a emenda, o deputado escolhe a modalidade de aplicação, e, portanto, pode decidir se a execução será realizada por meio de um ator local ou executada de forma centralizada. Nesse sentido, os resultados mostram que as transferências ao governo municipal são a modalidade com coeficiente significativo em todos os modelos. As demais modalidades, por outro lado, aparecem significantes apenas em dois dos seis modelos, ainda assim com coeficientes quase sempre inferiores aos das transferências às prefeituras. 
Tabela 3

Efeito das emendas, discriminando-as segundo a modalidade de aplicação

\begin{tabular}{|c|c|c|c|c|c|c|}
\hline & $\begin{array}{l}\text { Modelo } \\
\text { Empenho }\end{array}$ & $\begin{array}{c}\text { Modelo } \\
\text { Empenho } \\
e \\
\text { Pop }<200\end{array}$ & $\begin{array}{l}\text { Modelo } \\
\text { Empenho } \\
\text { por eleitor }\end{array}$ & $\begin{array}{c}\text { Modelo } \\
\text { Empenho } \\
\text { por eleitor } \\
\text { e } \\
\text { Pop }<200\end{array}$ & $\begin{array}{l}\text { Modelo } \\
\text { Log log }\end{array}$ & $\begin{array}{c}\text { Modelo } \\
\text { Log log e } \\
\text { Pop }<200\end{array}$ \\
\hline \multirow{2}{*}{$\begin{array}{l}\text { Emendas - } \\
\text { governo } \\
\text { estadual }\end{array}$} & $-0,20$ & $-0,49$ & $-3,92$ & $-5,11$ & 0,016 & 0,028 \\
\hline & $(0,30)$ & $(0,64)$ & $(0,40)$ & $(0,52)$ & $(2,05)^{*}$ & $(7,86)^{* *}$ \\
\hline \multirow{2}{*}{$\begin{array}{l}\text { Emendas - } \\
\text { governo } \\
\text { municipal (H2) }\end{array}$} & $0,90 * *$ & $0,67 *$ & $1,72 * *$ & $1,70 * *$ & $0,028^{* *}$ & $0,011 * *$ \\
\hline & $(2,66)$ & $(2,51)$ & $(5,29)$ & $(5,24)$ & $(12,84)$ & $(3,53)$ \\
\hline \multirow{2}{*}{$\begin{array}{l}\text { Emendas - } \\
\text { ESFL }\end{array}$} & $-0,45$ & $-0,02$ & 4,42 & 4,42 & $0,011 * *$ & $0,0103 *$ \\
\hline & $(0,36)$ & $(0,05)$ & $(0,63)$ & $(0,63)$ & $(2,66)$ & $(2,33)$ \\
\hline \multirow{2}{*}{$\begin{array}{l}\text { Emenda - } \\
\text { governo federal }\end{array}$} & $-0,37$ & $-0,19$ & 3,06 & 2,27 & $-0,009 *$ & $-0,008^{*}$ \\
\hline & $(0,28)$ & $(0,40)$ & $(0,68)$ & $(0,52)$ & $(2,50)$ & $(2,03)$ \\
\hline \multirow{2}{*}{$\begin{array}{l}\text { Pertencer ao } \\
\text { partido do } \\
\text { governador }\end{array}$} & 6,93 & 9,40 & 7,34 & 9,40 & $-0,025$ & $-0,023$ \\
\hline & $(0,81)$ & $(1,15)$ & $(0,84)$ & $(1,13)$ & $(1,89)$ & $(1,78)$ \\
\hline \multirow{2}{*}{ Dummy_troca } & $-16,96 *$ & $-13,55^{*}$ & $-16,53 *$ & $-13,26 *$ & $\begin{array}{c}- \\
0,065 * *\end{array}$ & $-0,065^{* *}$ \\
\hline & $(2,09)$ & $(2,47)$ & $(2,00)$ & $(2,37)$ & $(6,51)$ & $(6,54)$ \\
\hline \multirow{2}{*}{$\begin{array}{l}\text { Pertencer ao } \\
\text { partido do } \\
\text { prefeito }\end{array}$} & $67,47 * *$ & $66,11 * *$ & $80,30 * *$ & $74,83 * *$ & $0,104 * *$ & $0,100 * *$ \\
\hline & $(5,97)$ & $(8,35)$ & $(6,53)$ & $(10,21)$ & $(8,47)$ & $(8,17)$ \\
\hline \multirow{2}{*}{$\begin{array}{l}\text { Pertencer ao } \\
\text { partido do } \\
\text { presidente }\end{array}$} & $34,88^{*}$ & $32,03 *$ & $35,01^{*}$ & $32,05^{*}$ & $0,175 * *$ & $0,174 * *$ \\
\hline & $(2,26)$ & $(2,21)$ & $(2,14)$ & $(2,11)$ & $(4,20)$ & $(4,18)$ \\
\hline \multirow{2}{*}{$\begin{array}{l}\text { Número de } \\
\text { legislaturas }\end{array}$} & $-11,15$ & 2,98 & $-9,49$ & 4,52 & $0,074 * *$ & $0,074 * *$ \\
\hline & $(1,20)$ & $(0,69)$ & $(1,02)$ & $(1,05)$ & $(8,71)$ & $(8,67)$ \\
\hline$R^{2}$ ajustado & 0,78 & 0,85 & 0,78 & 0,85 & 0,79 & 0,79 \\
\hline $\mathrm{F}$ & 10,03 & 15,07 & 13,15 & 16,70 & 62,76 & 61,05 \\
\hline $\mathrm{N}$ & 420.105 & 419.536 & 420.105 & 419.536 & 420.105 & 419.536 \\
\hline
\end{tabular}

Fonte: Elaboração própria com base nos dados do SIGA Brasil, CEPESPdata e site da Câmara dos Deputados.

Estatísticas t robustas entre parênteses.

$*, * *, * * *$ indicam significância a $90 \%, 95 \%$ e $99 \%$, respectivamente.

Efeito fixo para deputado-município em todos os modelos.

No entanto, mesmo as transferências a prefeituras apresentaram efeito eleitoral restrito. O coeficiente do primeiro modelo, por exemplo, mostra que cada mil reais geraria pouco menos de um voto. Considerando que o deputado médio consegue o empenho de, aproximadamente, 5 milhões de reais, as emendas poderiam significar um acréscimo de 5 mil votos. Esse aumento na votação pode ser decisivo para alguns deputados, mas não chega a ser determinante para a maioria deles.

A Tabela 4 mostra a relação entre votação nominal dos candidatos a deputados e resultado eleitoral final da eleição de 2014, considerando os dois estados situados nos extremos do ranking de população. No estado de Roraima, por exemplo, os 5 mil votos 
facilmente levariam o deputado até o último decil de votos, em que as chances de conquistar uma cadeira são elevadas. Por outro lado, os 5 mil votos não seriam de grande ajuda para o deputado paulista que buscasse figurar entre os integrantes do último decil de votos.

Quando se considera o modelo em que a variável explicativa é a emenda por eleitor, a magnitude é ainda menor, uma vez que o deputado brasileiro médio consegue obter o empenho aproximado de 58 reais por eleitor atendido. Considerando que um deputado aplique, por exemplo, 5 milhões de reais em um município com 10 mil habitantes, a quantidade de votos auferida pelo político seria de apenas 850 votos $^{7}$.

Outras modalidades de aplicação dos recursos, como as transferências aos governos estaduais, não têm efeito significativo nos votos na maior parte dos modelos. É provável que essas emendas não tenham como fim imediato conseguir votos no município, e sim obter apoio do governador.

A presença de emendas que não visam ao voto no local beneficiado pode explicar, em parte, a dificuldade que os pesquisadores anteriores tiveram em captar o efeito eleitoral desses repasses. As emendas com fins eleitorais estão diluídas em outros tipos de recursos, levando pesquisadores a considerar que o efeito das emendas, em geral, é nulo, quando na verdade as transferências a prefeituras têm significância estatística, ainda que com impacto tímido.

\footnotetext{
7 Os 5 milhões em um município de 10 mil habitantes equivaleriam a um aumento de 500 unidades na variável explicativa. Como o coeficiente gira em torno de 1,7 nas especificações "por eleitor" da Tabela 3, aquele aumento hipotético produziria 850 votos $(500 \times 1,7)$.
} 
Tabela 4

Relação entre votação nominal dos candidatos a deputado e resultado eleitoral final

\begin{tabular}{|c|c|c|c|c|c|c|}
\hline Decil & Estado & $\begin{array}{c}\text { Intervalo } \\
\text { de votos }\end{array}$ & $\begin{array}{c}\text { Média de } \\
\text { votos }\end{array}$ & $\begin{array}{c}\text { \% de } \\
\text { derrotados }\end{array}$ & $\begin{array}{c}\text { \% de } \\
\text { suplentes }\end{array}$ & $\begin{array}{c}\text { \% de } \\
\text { eleitos }\end{array}$ \\
\hline 1 & RR & $2-23$ & 14,22 & 22,22 & 77,77 &. \\
\hline 2 & RR & $24-85$ & 39,00 & 14,28 & 85,71 &. \\
\hline 3 & RR & $86-164$ & 122,25 & 25,00 & 75,00 &. \\
\hline 4 & RR & $180-377$ & 265,87 & 12,50 & 87,50 &. \\
\hline 5 & RR & $380-581$ & 483,00 & 12,50 & 87,50 &. \\
\hline 6 & RR & $625-955$ & 785,62 & 25,00 & 75,00 &. \\
\hline 7 & RR & $961-2.067$ & $1.507,00$ & 25,00 & 75,00 &. \\
\hline 8 & RR & $2.676-5.054$ & $3.780,37$ &. & 100,00 &. \\
\hline 9 & RR & $5.156-6.782$ & $6.141,00$ & 12,50 & 75,00 & 12,50 \\
\hline 10 & RR & $7.481-$ & $16.164,88$ & 12,50 & & 87,50 \\
\hline 1 & SP & $6-157$ & 87,43 & 44,02 & 55,98 & - \\
\hline 2 & SP & $158-283$ & 217,78 & 37,69 & 62,31 & - \\
\hline 3 & SP & $284-492$ & 376,26 & 37,31 & 63,69 & - \\
\hline 4 & SP & $494-691$ & 583,30 & 30,77 & 69,23 & - \\
\hline 5 & SP & $692-1.061$ & 854,34 & 27,48 & 72,52 & - \\
\hline 6 & SP & $1.062-1.816$ & $1.376,50$ & 25,75 & 74,25 & - \\
\hline 7 & SP & $1.829-3.007$ & $2.361,31$ & 31,81 & 68,19 & - \\
\hline 8 & SP & $3.015-7.587$ & $4.769,85$ & 18,18 & 81,82 & - \\
\hline 9 & SP & $7.625-$ & $16.142,71$ & 10,61 & 86,36 & 3,03 \\
\hline 10 & SP & $32.622-$ & $119.799,30$ & 2,29 & 47,33 & 50,38 \\
\hline
\end{tabular}

Fonte: Elaboração própria com base nos dados do CEPESPdata.

Observação: Dados referentes à eleição de 2014 para a Câmara dos Deputados.

Esses resultados permitem confirmar a $\mathrm{H} 2$, mostrando que as emendas cujo dinheiro circula dentro dos cofres do governo municipal são aquelas que trazem retorno eleitoral. O problema da reclamação de crédito em distritos grandes (Lancaster, 1986), portanto, parece ser contornado por meio do apoio local dos prefeitos. O prefeito se une ao deputado para receber benefícios do orçamento da União e, em troca, garante que parlamentares rivais não "peguem carona" no esforço do aliado.

Se existe uma aliança entre deputado e prefeito em torno das emendas, vale questionar até que ponto essa ligação é influenciada pelas organizações partidárias. No Brasil, vigorou durante um certo tempo a tese de que os partidos seriam fracos (Mainwaring, 1993a, 1993b; Ames, 1995a), apesar de resultados empíricos terem 
paulatinamente fragilizado essa hipótese (Carneiro e Almeida, 2008; Avelino, Biderman e Barone, 2012; Barone, 2014). Este artigo se insere nesse debate verificando se a aliança entre prefeito e deputado, no contexto das emendas, tem conteúdo partidário. Caso tenha, emendas enviadas para prefeituras dominadas por um colega de partido surtirão efeito maior nas urnas. Em termos teóricos, esse resultado apontaria a força do partido como articulador de diferentes atores políticos na arena eleitoral.

A Tabela 5 mostra os coeficientes da interação entre as emendas e o pertencimento ao partido do prefeito. Quando o deputado é do mesmo partido que o prefeito, o efeito do pork aumenta em quatro dos seis modelos. A depender da especificação, a emenda enviada para a prefeitura correligionária chega a ter efeito até três vezes superior à emenda enviada para prefeituras de outros partidos. 
Tabela 5

Efeito da interação entre emendas totais e conexão partidária deputado-prefeito

\begin{tabular}{|c|c|c|c|c|c|c|}
\hline & $\begin{array}{l}\text { Modelo } \\
\text { Empenho }\end{array}$ & $\begin{array}{c}\text { Modelo } \\
\text { Empenho } \\
\text { e } \\
\text { Pop }<200\end{array}$ & $\begin{array}{l}\text { Modelo } \\
\text { Empenho } \\
\text { por eleitor }\end{array}$ & $\begin{array}{c}\text { Modelo } \\
\text { Empenho } \\
\text { por eleitor } \\
\text { e } \\
\text { Pop }<200\end{array}$ & $\begin{array}{l}\text { Modelo } \\
\text { Log log }\end{array}$ & $\begin{array}{c}\text { Modelo } \\
\text { Log log e } \\
\text { Pop }<200\end{array}$ \\
\hline \multirow{2}{*}{$\begin{array}{l}\text { Pertencer ao } \\
\text { partido do } \\
\text { prefeito * } \\
\text { Emendas totais } \\
\text { (H3) }\end{array}$} & 0,78 & 0,29 & $1,94 * *$ & $1,91 * *$ & $0,015 * *$ & $0,016 * *$ \\
\hline & $(1,15)$ & $(0,94)$ & $(2,63)$ & $(2,62)$ & $(3,97)$ & $(3,94)$ \\
\hline \multirow{2}{*}{ Emendas totais } & 0,24 & 0,08 & $1,07 * *$ & $1,04^{*}$ & $0,021 * *$ & $0,022 * *$ \\
\hline & $(0,79)$ & $(0,39)$ & $(2,64)$ & $(2,57)$ & $(10,16)$ & $(10,14)$ \\
\hline \multirow{2}{*}{$\begin{array}{l}\text { Pertencer ao } \\
\text { partido do } \\
\text { governador }\end{array}$} & 6,98 & 9,10 & 7,08 & 9,10 & $-0,024$ & $-0,024$ \\
\hline & $(0,81)$ & $(1,10)$ & $(0,80)$ & $(1,09)$ & $(1,86)$ & $(1,83)$ \\
\hline \multirow{2}{*}{ Dummy_troca } & $-15,64$ & $-13,18^{*}$ & $-16,50 *$ & $-13,23 *$ & $0,065^{-} *$ & $-0,065^{* *}$ \\
\hline & $(1,90)$ & $(2,34)$ & $(1,99)$ & $(2,36)$ & $(6,49)$ & $(6,48)$ \\
\hline \multirow{2}{*}{$\begin{array}{l}\text { Pertencer ao } \\
\text { partido do } \\
\text { prefeito }\end{array}$} & $51,60 * *$ & $65,89 * *$ & $77,37 * *$ & $71,95 * *$ & $0,095 * *$ & $0,095 * *$ \\
\hline & $(3,37)$ & $(7,10)$ & $(6,35)$ & $(10,13$ & $(7,58)$ & $(7,58)$ \\
\hline \multirow{2}{*}{$\begin{array}{l}\text { Pertencer ao } \\
\text { partido do } \\
\text { presidente }\end{array}$} & 30,32 & 29,48 & $33,93^{*}$ & $30,90 *$ & $0,173 * *$ & $0,173 * *$ \\
\hline & $(1,73)$ & $(1,91)$ & $(2,07)$ & $(2,04)$ & $(4,17)$ & $(4,17)$ \\
\hline \multirow{2}{*}{$\begin{array}{l}\text { Número de } \\
\text { legislaturas }\end{array}$} & $-10,50$ & 4,43 & $-9,31$ & 4,71 & $0,074 * *$ & $0,074 * *$ \\
\hline & $(1,10)$ & $(1,04)$ & $(1,00)$ & $(1,10)$ & $(8,72)$ & $(8,72)$ \\
\hline $\mathrm{R}^{2}$ ajustado & 0,78 & 0,85 & 0,78 & 0,85 & 0,79 & 0,79 \\
\hline $\mathrm{F}$ & 12,59 & 19,05 & 15,27 & 20,16 & 76,43 & 74,54 \\
\hline $\mathrm{N}$ & 420.105 & 419.536 & 420.105 & 419.536 & 420.105 & 419.536 \\
\hline
\end{tabular}

Fonte: Elaboração própria com base nos dados do SIGA Brasil, CEPESPdata e site da Câmara dos Deputados.

Estatísticas t robustas entre parênteses.

$*, * *, * * *$ indicam significância a 90\%, 95\% e 99\%, respectivamente.

Efeito fixo para deputado-município em todos os modelos.

Portanto, há uma interação positiva entre as emendas e o alinhamento partidário do prefeito com o deputado, mesmo nos modelos apresentados na Tabela 5, em que não se discriminaram as emendas em função de sua modalidade de aplicação. Esses resultados surpreendem em alguma medida, uma vez que alguns tipos de emendas provavelmente não são utilizados para conquistar o apoio do prefeito. É provável, por exemplo, que o deputado prefira enviar suas emendas para serem executadas por ONGs locais ou pelo governo federal quando o prefeito não for aliado. Ao mesmo tempo, o prefeito associado ao parlamentar irá preferir receber os recursos por meio dos cofres da prefeitura, em vez de isso ocorrer por outros canais. Desse modo, é razoável supor que apenas as emendas enviadas diretamente para as prefeituras tenham o condão de angariar o apoio do político 
local. Esse efeito estaria diluído nos modelos da Tabela 5, uma vez que as emendas estão todas concentradas em uma única variável.

Na Tabela 6, busca-se superar a aglutinação das emendas, separando-as de acordo com o ator escolhido pelo deputado para realizar a execução orçamentária. Observando a interação entre o alinhamento partidário de deputado e prefeito e as emendas aplicadas a cada uma das modalidades, é possível constatar que as transferências às prefeituras são as responsáveis por selar a aliança entre os dois políticos. Enquanto as demais modalidades não apresentam coeficientes positivos ou significativos, em metade dos modelos pode-se captar a interação entre o copartidarismo e a transferência ao governo local. As evidências, portanto, sugerem a aceitação da H3.

Esses resultados, como um todo, têm três implicações teóricas. Em primeiro lugar, os números mostram que as emendas têm efeito tímido nos votos, estando longe de ser o principal instrumento que os legisladores utilizariam para se reeleger. Portanto, o estímulo ao voto pessoal não é suficiente para elevar as emendas à condição de peça vital da sobrevivência política, apesar de parte da literatura ter assumido esse pressuposto. É provável que vários outros objetivos estejam por trás do uso político das emendas pelos deputados, além da reeleição.

Em segundo lugar, o prefeito é o ator-chave que permite que deputados obtenham alguma vantagem eleitoral, ainda que pequena. Para usar os termos da literatura sobre clientelismo em democracias em desenvolvimento, pode-se dizer que o prefeito é o principal broker político no contexto de aprovação e implementação das emendas.

Por fim, esses resultados mostram que o partido é capaz de articular a aliança entre atores situados em diferentes pontos do sistema político, uma vez que a reclamação de crédito pelo dinheiro enviado às prefeituras é facilitada quando prefeito e deputado compartilham a mesma sigla partidária. As relações partidárias, portanto, reforçam vínculos de natureza puramente local ou pessoal que possa haver entre prefeitos e deputados (Cf. Bezerra, 2001, p. 193). 
Tabela 6

Efeito da interação entre emendas totais e conexão partidária deputadoprefeito, segregando as emendas conforme modalidade de aplicação

\begin{tabular}{|c|c|c|c|c|c|c|}
\hline & $\begin{array}{l}\text { Modelo } \\
\text { Empenho }\end{array}$ & $\begin{array}{c}\text { Modelo } \\
\text { Empenho } \\
\text { e } \\
\text { Pop<200 }\end{array}$ & $\begin{array}{l}\text { Modelo } \\
\text { Empenho } \\
\text { por eleitor }\end{array}$ & $\begin{array}{c}\text { Modelo } \\
\text { Empenho } \\
\text { por eleitor } \\
\text { e } \\
\text { Pop<200 } \\
\end{array}$ & $\begin{array}{l}\text { Modelo } \\
\text { Log log }\end{array}$ & $\begin{array}{l}\text { Modelo } \\
\text { Log log e } \\
\text { Pop }<200\end{array}$ \\
\hline \multirow{2}{*}{$\begin{array}{l}\text { Pertencer ao } \\
\text { partido do } \\
\text { prefeito* } \\
\text { Emendas - gov. } \\
\text { estadual }\end{array}$} & 1,72 & 1,74 & 9,03 & 10,42 & 0,021 & 0,005 \\
\hline & $(0,79)$ & $(1,02)$ & $(0,36)$ & $(0,41)$ & $(0,88)$ & $(0,53)$ \\
\hline \multirow{2}{*}{$\begin{array}{l}\text { Pertencer ao } \\
\text { partido do } \\
\text { prefeito* } \\
\text { Emendas - gov. } \\
\text { municipal (H3) }\end{array}$} & 0,87 & 0,023 & 1,91 & 1,85 & 0,018 & 0,008 \\
\hline & $(1,18)$ & $(0,07)$ & $(2,53)^{*}$ & $(2,48)^{*}$ & $(3,95)^{* *}$ & $(1,07)$ \\
\hline \multirow{2}{*}{$\begin{array}{l}\text { Pertencer ao } \\
\text { partido do } \\
\text { prefeito } * \\
\text { Emendas - ESFL }\end{array}$} & 0,65 & 0,55 & $-15,64$ & $-16,34$ & $-0,022$ & $-0,021$ \\
\hline & $(0,34)$ & $(0,42)$ & $(0,55)$ & $(0,58)$ & $(1,96)^{*}$ & $(1,72)$ \\
\hline \multirow{2}{*}{$\begin{array}{l}\text { Pertencer ao } \\
\text { partido do } \\
\text { prefeito* Emenda } \\
\text { - gov. federal }\end{array}$} & $-1,07$ & 0,49 & 14,08 & 15,21 & $-0,002$ & $-0,000$ \\
\hline & $(0,35)$ & $(0,26)$ & $(0,99)$ & $(1,08)$ & $(0,18)$ & $(0,07)$ \\
\hline \multirow{2}{*}{$\begin{array}{l}\text { Emendas - gov. } \\
\text { estadual }\end{array}$} & $-0,62$ & $-1,07$ & $-5,35$ & $-6,71$ & 0,013 & 0,025 \\
\hline & $(0,80)$ & $(1,82)$ & $(0,48)$ & $(0,61)$ & $(1.56)$ & $(6,15)^{* *}$ \\
\hline \multirow{2}{*}{$\begin{array}{l}\text { Emendas - gov. } \\
\text { municipal }\end{array}$} & 0,16 & 0,37 & 1,02 & 1,01 & 0,023 & 0,010 \\
\hline & $(0,45)$ & $(1,38)$ & $(2,77)^{* *}$ & $(2,77)^{* *}$ & $(9,71)^{* *}$ & $(2,88)^{* *}$ \\
\hline \multirow{2}{*}{ Emendas - ESFL } & 0,51 & $-0,13$ & 6,17 & 6,25 & 0,014 & 0,013 \\
\hline & $(0,56)$ & $(0,41)$ & $(0,88)$ & $(0,90)$ & $(3,49) * *$ & $(3,05)^{* *}$ \\
\hline \multirow{2}{*}{$\begin{array}{l}\text { Emenda - gov. } \\
\text { federal }\end{array}$} & 1,35 & $-0,25$ & 0,77 & $-0,21$ & $-0,009$ & $-0,007$ \\
\hline & $(0,59)$ & $(0,66)$ & $(0,16)$ & $(0,05)$ & $(2,12)^{*}$ & $(1,77)$ \\
\hline \multirow{2}{*}{$\begin{array}{l}\text { Pertencer ao } \\
\text { partido do } \\
\text { governador }\end{array}$} & 8,53 & 9,70 & 7,31 & 9,35 & $-0,024$ & $-0,02$ \\
\hline & $(0,99)$ & $(1,20)$ & $(0,83)$ & $(1,13)$ & $(1,86)$ & $(1,76)$ \\
\hline \multirow{2}{*}{ Dummy_troca } & $-15,12$ & $-12,42$ & $-16,47$ & $-13,20$ & $-0,065$ & $-0,065$ \\
\hline & $(1,92)$ & $(2,21)^{*}$ & $(1,99)^{*}$ & $(2,36)^{*}$ & $(6,50) * *$ & $(6,54)^{* *}$ \\
\hline \multirow{2}{*}{$\begin{array}{l}\text { Pertencer ao } \\
\text { partido do } \\
\text { prefeito }\end{array}$} & 52,01 & 68,00 & 77,46 & 72,03 & 0,095 & 0,095 \\
\hline & $(3,41)^{* *}$ & $(7,24)^{* *}$ & $(6,39)^{* *}$ & $(10,28)^{* *}$ & $(7,64)^{* *}$ & $(7,61)^{* *}$ \\
\hline \multirow{2}{*}{$\begin{array}{l}\text { Pertencer ao } \\
\text { partido do } \\
\text { presidente }\end{array}$} & 28,84 & 30,37 & 33,82 & 30,83 & 0,173 & 0,173 \\
\hline & $(1,64)$ & $(2,02)^{*}$ & $(2,07)^{*}$ & $(2,03)^{*}$ & $(4,16)^{* *}$ & $(4,16)^{* *}$ \\
\hline \multirow{2}{*}{$\begin{array}{l}\text { Número de } \\
\text { legislaturas }\end{array}$} & $-10,42$ & 3,69 & $-9,32$ & 4,69 & 0,074 & 0,074 \\
\hline & $(1,16)$ & $(0,87)$ & $(1,00)$ & $(1,09)$ & $(8,73) * *$ & $(8,70)^{* *}$ \\
\hline $\mathrm{F}$ & 8,77 & 12,10 & 9,94 & 13,18 & 46,83 & 45,60 \\
\hline $\mathrm{R}^{2}$ ajustado & 0,78 & 0,86 & 0,78 & 0,85 & 0,79 & 0,79 \\
\hline $\mathrm{N}$ & 420.105 & 419.536 & 420.105 & 419.536 & 420.105 & 419.536 \\
\hline
\end{tabular}

Fonte: Elaboração própria com base nos dados do SIGA Brasil, CEPESPdata e site da Câmara dos

Deputados.

Estatísticas t robustas entre parênteses.

Estatísticas t robustas entre parênteses.

$*, * *, * * *$ indicam significância a $90 \%, 95 \%$ e $99 \%$, respectivamente.

Efeito fixo para deputado-município em todos os modelos. 


\section{A alocação das emendas pelos partidos}

A fim de complementar a análise sobre a conexão intrapartidária, buscou-se analisar como a presença de um colega de partido na prefeitura afeta as emendas enviadas pelos deputados. As regressões descontínuas realizadas contaram com as variáveis dependentes $^{8}: 1$ ) valor proposto; 2) valor proposto por eleitor; 3) valor empenhado; 4) valor empenhado por eleitor. Além disso, considerou-se apenas a modalidade de aplicação em que o recurso é enviado diretamente para a prefeitura.

As Figuras 4 e 5 apresentam graficamente os valores médios, condicionais à margem de voto, das emendas propostas e empenhadas. A metade à direita da linha vermelha, em cada um dos quatro gráficos, apresenta os valores em que a margem de votação foi positiva, ou seja, os valores dos vencedores. A metade à esquerda da linha vermelha, por sua vez, apresenta os valores dos perdedores. Percebe-se em todos os gráficos que há um salto positivo quando o partido ganha.

Figura 4

Emendas propostas pelos partidos vencedores e perdedores

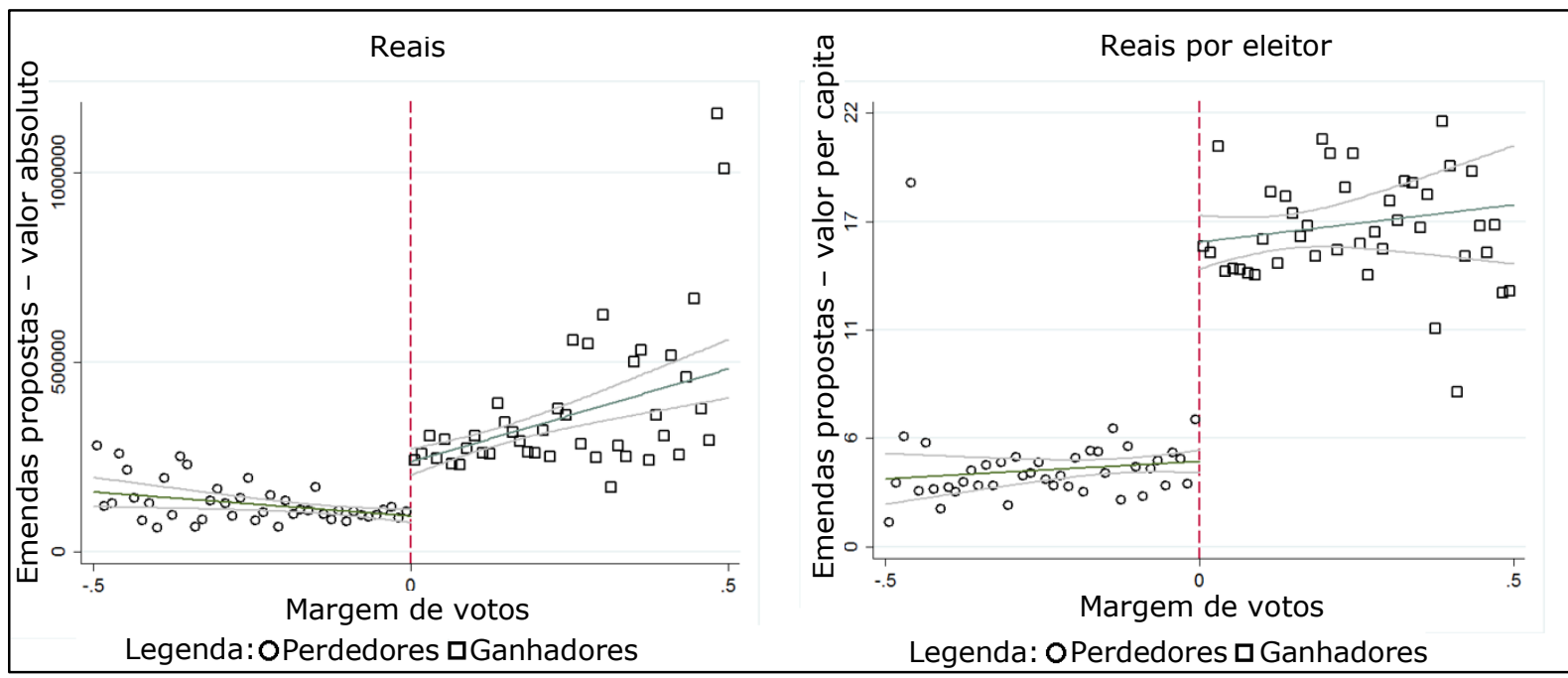

Fonte: Elaboração própria com base nos dados do SIGA Brasil e CEPESPdata.

\footnotetext{
8 Ao operacionalizar a variável dependente, as emendas individuais dos deputados foram agregadas por partido. Assim, a unidade de observação é o município-partido, que pode ter recebido o tratamento (vitória) ou não (derrota). Para cada município, portanto, há duas observações, correspondentes aos dois partidos que disputaram a eleição para prefeito. Em cada município, a margem de votação é simétrica para os dois partidos, mas com sinais opostos.
} 
Figura 5

Emendas empenhadas pelos partidos vencedores e perdedores

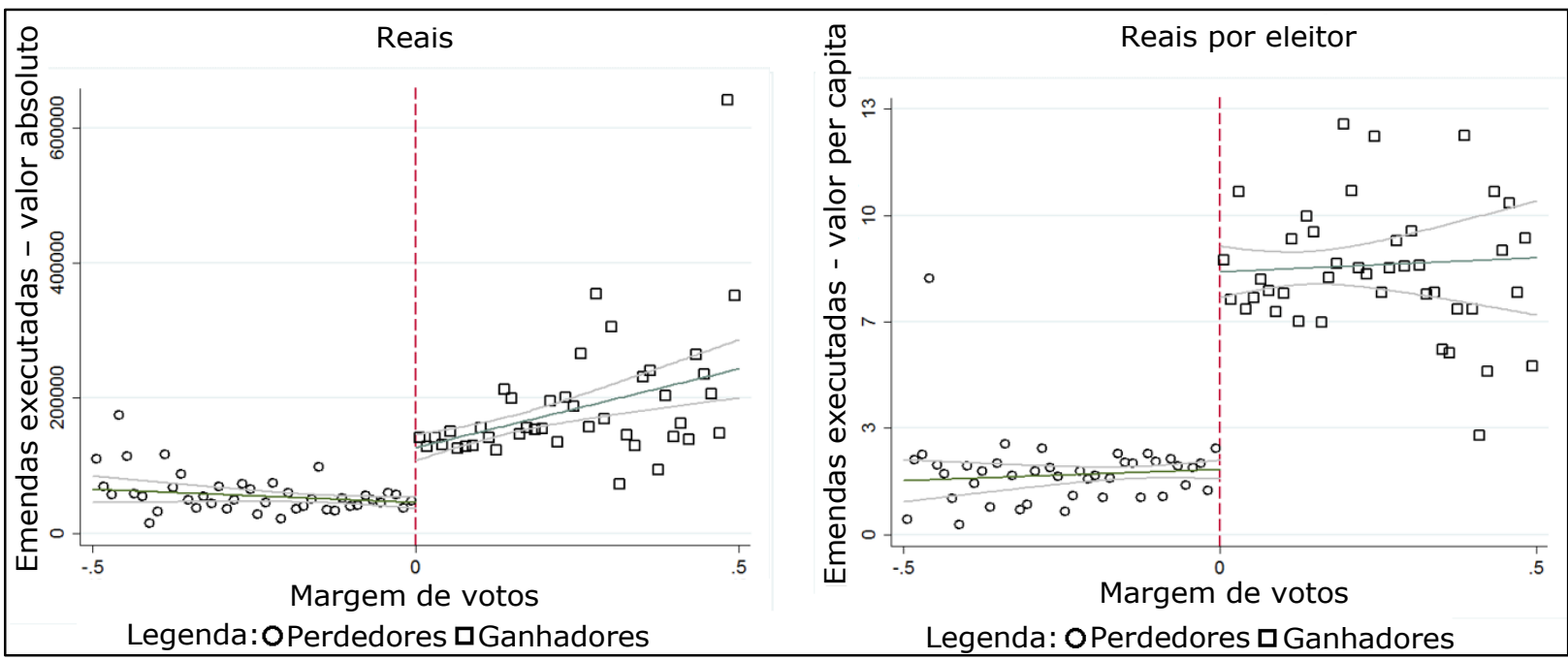

Fonte: Elaboração própria com base nos dados do SIGA Brasil e CEPESPdata.

Os resultados da Tabela 7, por sua vez, apresentam os resultados dos modelos utilizados para inferir o valor e a significância do tratamento. Na maior parte das especificações, o tratamento teve efeito positivo e significativo, indicando que os deputados de um partido enviam e empenham mais emendas aos municípios em que sua sigla vence. 


\section{Tabela 7 \\ Impacto da vitória do partido no valor enviado à prefeitura por meio das emendas individuais dos deputados copartidários}

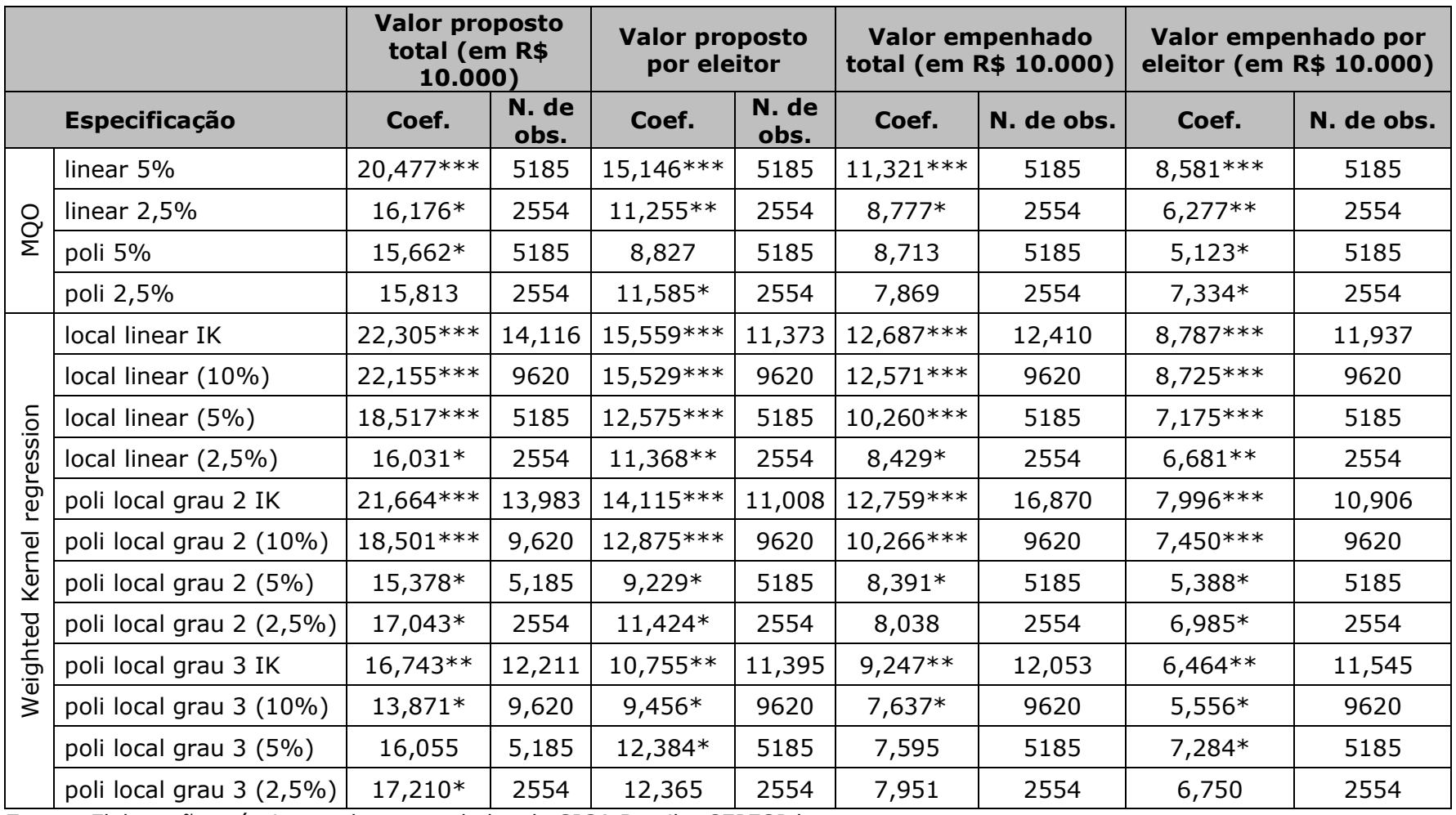

Fonte: Elaboração própria com base nos dados do SIGA Brasil e CEPESPdata.

\section{Observações:}

Os percentuais entre parênteses se referem à "largura da banda" (bandwidth), que pode ter sido atribuída manualmente ou pelo método IK.

O peso das regressões ponderadas utilizou uma função Kernel triangular.

Informações pormenorizadas sobre as formas funcionais aplicadas são fornecidas no Apêndice 1.

-*, **, *** indicam significância a 90\%, 95\% e 99\%, respectivamente.

Esses resultados reforçam a ideia de que emendas enviadas para prefeituras correligionárias são mais eficazes, pois são justamente essas prefeituras as que recebem mais atenção dos deputados no momento de enviar os recursos. Percebe-se, assim, a relevância da conexão partidária tanto na alocação das emendas quanto em seu aproveitamento político pelos deputados.

Regressões descontínuas partem do pressuposto de que ganhar ou perder a eleição por poucos votos é determinado aleatoriamente. Caso isso seja verdade, os ganhadores e perdedores serão muito similares em média, e, consequentemente, diferenças observadas após a eleição poderão ser atribuídas exclusivamente ao evento eleitoral. Caughey e Sekhon (2011) mostram que essa premissa nem sempre vale para o Congresso americano, enquanto Eggers et al. (2015) apontam que, em um determinado grupo de eleições - 
incluindo as que elegem os prefeitos brasileiros - os dois grupos seriam similares nas eleições acirradas.

Para se resguardarem de eventuais diferenças não observáveis entre os grupos de vencedores e perdedores selecionados para a regressão descontínua, é comum testar se a vitória afeta eventos passados ou variáveis sabidamente não relacionadas à eleição. Caso haja aleatoriedade na seleção entre os dois grupos e similaridade em suas características, espera-se que a vitória ou a derrota não tenham nenhuma associação com eventos passados ou não relacionados à eleição.

Por esse motivo, no Apêndice 2 é apresentado o resultado de regressões descontínuas em que se analisa o efeito da vitória eleitoral de um partido nas emendas enviadas por ele antes do pleito eleitoral. Também foi aplicada uma regressão para estudar o efeito da vitória nos resultados passados do partido. Conforme esperado, nenhum coeficiente despontou na análise como significativo, indicando a simetria de características entre os dois grupos e ratificando a validade do desenho de pesquisa.

Síntese dos resultados e das contribuições

O Quadro 3 busca sintetizar as constatações empíricas, as contribuições teóricas do trabalho e o estado corrente da literatura sobre o assunto:

Quadro 3

Síntese das principais contribuições empíricas e teóricas do trabalho

\begin{tabular}{|l|l|l|}
\hline $\begin{array}{c}\text { Constatação } \\
\text { empírica }\end{array}$ & \multicolumn{1}{|c|}{ Estado atual da literatura } & \multicolumn{1}{c|}{ Contribuição do artigo } \\
\hline $\begin{array}{l}\text { Emenda gera voto } \\
\text { (H1) }\end{array}$ & $\begin{array}{l}\text { Os resultados oscilaram muito } \\
\text { entre os últimos trabalhos } \\
\text { (Samuels, 2002; Pereira e Rennó, } \\
2007 ; \text { Mesquita, 2008; Firpo, } \\
\text { Ponczek e Sanfelice, 2014), sem } \\
\text { convergir para um consenso sobre } \\
\text { a existência de efeitos relevantes anteriores podem ter tido } \\
\text { no resultado eleitoral devido a limitações } \\
\text { das emendas nas eleições para a a contabilidade pública que dificultam } \\
\text { associar a execução de uma emenda ao } \\
\text { râmara dos Deputados. }\end{array}$ & $\begin{array}{l}\text { Após corrigir os dados para contornar essa } \\
\text { limitação, o resultado do presente artigo } \\
\text { revelou um efeito positivo e significativo } \\
\text { das emendas na maioria dos modelos. } \\
\text { Assim, ainda que a magnitude seja restrita } \\
\text { nas regressões em que se testou a H1, é } \\
\text { possível afirmar que as emendas realmente } \\
\text { melhoram, em alguma medida, o resultado } \\
\text { eleitoral do parlamentar. }\end{array}$ \\
\hline
\end{tabular}




\begin{tabular}{|c|c|c|}
\hline $\begin{array}{c}\text { Constatação } \\
\text { empírica }\end{array}$ & Estado atual da literatura & Contribuição do artigo \\
\hline $\begin{array}{l}\text { Dentre as } \\
\text { emendas, as } \\
\text { executadas por } \\
\text { prefeituras são as } \\
\text { que geram votos } \\
\text { (H2) }\end{array}$ & $\begin{array}{l}\text { Os trabalhos anteriores } \\
\text { consideraram o incentivo ao voto } \\
\text { pessoal como suficiente para } \\
\text { pressupor a presença de pork barrel } \\
\text { politics no Brasil, ignorando que a } \\
\text { magnitude do distrito deveria } \\
\text { representar um empecilho ao } \\
\text { surgimento desse fenômeno } \\
\text { (Lancaster, 1986). Dessa forma, } \\
\text { ainda que se presuma um efeito } \\
\text { eleitoral positivo das emendas, } \\
\text { permanece desconhecido o } \\
\text { mecanismo causal que estaria por } \\
\text { trás da conversão desses recursos } \\
\text { em resultado nas urnas. } \\
\text { Trabalhos anteriores não } \\
\text { avançaram nesse ponto, em parte } \\
\text { porque utilizaram as emendas } \\
\text { como um todo, sem discriminá-las } \\
\text { segundo suas características. Da } \\
\text { mesma forma, nenhum trabalho } \\
\text { anterior explorou o papel dos } \\
\text { prefeitos na conversão de emendas } \\
\text { em votos. }\end{array}$ & $\begin{array}{l}\text { Este artigo separa as emendas segundo o } \\
\text { ator responsável pela execução, mostrando } \\
\text { que as emendas executadas por prefeituras } \\
\text { são as que geram votos. Isso sugere um } \\
\text { papel do prefeito enquanto broker político } \\
\text { no contexto das emendas. } \\
\text { Esse resultado também explica como os } \\
\text { deputados conseguem reclamar crédito das } \\
\text { emendas no Brasil, mesmo em face de } \\
\text { distritos de magnitude elevada. O prefeito } \\
\text { seria um broker cuja influência local } \\
\text { impediria que free-riders se aproveitassem } \\
\text { politicamente das benfeitorias decorrentes } \\
\text { de emendas. }\end{array}$ \\
\hline $\begin{array}{l}\text { O efeito positivo } \\
\text { da emenda no } \\
\text { voto é maior } \\
\text { quando há } \\
\text { alinhamento } \\
\text { partidário entre } \\
\text { deputado } \\
\text { propositor e } \\
\text { prefeito do } \\
\text { município } \\
\text { beneficiário }(\mathrm{H} 3)\end{array}$ & $\begin{array}{l}\text { Os trabalhos anteriores foram } \\
\text { omissos tanto sobre o papel dos } \\
\text { prefeitos quanto sobre a conexão } \\
\text { partidária entre esse ator e o } \\
\text { deputado, na conversão das } \\
\text { emendas em voto. }\end{array}$ & $\begin{array}{l}\text { Este artigo demonstra que o alinhamento } \\
\text { partidário entre prefeito e deputado } \\
\text { aumenta a eficácia das emendas enviadas } \\
\text { às prefeituras. Isso mostra que o partido é } \\
\text { importante para sedimentar a aliança entre } \\
\text { os dois atores. }\end{array}$ \\
\hline $\begin{array}{l}\text { O volume } \\
\text { proposto e } \\
\text { executado pelo } \\
\text { conjunto de } \\
\text { deputados de um } \\
\text { partido é maior } \\
\text { quando o prefeito } \\
\text { do município é do } \\
\text { mesmo partido } \\
(\mathrm{H} 4) .\end{array}$ & $\begin{array}{l}\text { O único trabalho encontrado } \\
\text { (Barone, 2014) que explorou essa } \\
\text { questão por meio de regressão } \\
\text { descontínua excluiu um ano } \\
\text { importante da análise (o ano } \\
\text { subsequente ao da eleição } \\
\text { municipal) e não utilizou dados de } \\
\text { execução, mas apenas de } \\
\text { proposição. Como o que importa, } \\
\text { ao final do processo, é que os } \\
\text { recursos efetivamente cheguem ao } \\
\text { destino, o presente artigo buscou } \\
\text { utilizar um desenho de pesquisa } \\
\text { similar ao de Barone (2014), mas } \\
\text { com novas variáveis e alguns } \\
\text { ajustes metodológicos. }\end{array}$ & $\begin{array}{l}\text { Este artigo mostra que o conjunto de } \\
\text { deputados de um partido tende a enviar } \\
\text { emendas para prefeituras correligionárias. } \\
\text { Da mesma forma, o volume empenhado } \\
\text { das emendas nestes municípios é maior, } \\
\text { mostrando que numa etapa inicial o } \\
\text { alinhamento partidário incentiva a } \\
\text { proposição e, após a emenda ter sido } \\
\text { inscrita na lei orçamentária, facilita o } \\
\text { empenho. } \\
\text { Esse resultado corrobora a importância do } \\
\text { prefeito correligionário no contexto das } \\
\text { emendas e ratifica a importância do partido } \\
\text { na coordenação dos atores na arena } \\
\text { eleitoral. }\end{array}$ \\
\hline
\end{tabular}

Fonte: Elaboração própria. 


\section{Considerações finais}

A literatura sobre o sistema político brasileiro é fortemente marcada pela previsão, baseada em características do sistema eleitoral, de que haveria intenso incentivo ao voto pessoal nas eleições para o Congresso Nacional. Segundo esse argumento, lista aberta e magnitude distrital elevada tornariam imprescindíveis as reputações pessoais nas disputas por voto.

As reputações pessoais, por sua vez, seriam construídas por meio de pork barrel politics, consubstanciadas na forma de emendas orçamentárias individuais. Surveys aplicados junto a eleitores e deputados reforçaram esse argumento, mostrando que os recursos enviados às bases locais por meio das emendas seriam valorizados tanto por políticos quanto por votantes.

No entanto, os resultados dos estudos empíricos que buscaram identificar o efeito eleitoral das emendas não convergiram para um consenso. Por esse motivo, a primeira hipótese do artigo busca tão somente retomar essa questão, testando novamente o efeito eleitoral desses recursos. A diferença é que se intenta, aqui, superar limitações metodológicas não observadas nos estudos anteriores. Uma dessas limitações residia na identificação da execução orçamentária das emendas. O governo brasileiro disponibiliza apenas a execução da programação atingida por uma emenda, e não a execução das emendas em si. Uma vez que muitas emendas afetam programações comuns, os dados de execução utilizados em trabalhos anteriores podem ter distorcido as conclusões alcançadas. A variável pork barrel, portanto, foi tratada para que refletisse a real contribuição do deputado para a execução de cada programação.

Além do mais, visando melhorar a validade interna dos modelos, foi utilizada uma especificação rigorosa de efeito fixo, controlando todos os fatores que não variavam para cada par deputado-município. Assim, fatores como um possível histórico de participação do deputado na Câmara dos Vereadores, qualidades carismáticas do parlamentar ou características idiossincráticas do município foram todos controlados.

O primeiro esforço do artigo buscou unicamente testar o efeito eleitoral das emendas de forma geral, sem discriminá-las segundo seus atributos. Os primeiros resultados apontaram efeito estatisticamente significante em alguns dos modelos, mas não substantivamente relevante. De acordo com as equações de regressão estimadas, emendas produziriam votos, mas em uma magnitude muito pequena para representar alguma vantagem eleitoral.

O segundo esforço apresentado neste artigo consistiu na separação das emendas em função da natureza do gasto. Mais especificamente, segregaram-se os recursos entre aqueles executados pelas prefeituras, governos estaduais, ONGs e pela União. A hipótese que guiou esta seção foi a de que apenas emendas executadas por prefeitos teriam eficácia eleitoral. Vários estudos apontam a influência dos prefeitos nas eleições nacionais, e, 
portanto, é razoável supor que conquistar o apoio desse ator político interesse eleitoralmente ao deputado. Ao separar as emendas, aquelas destinadas a prefeituras apresentaram coeficiente significativo em todos os modelos, confirmando a hipótese de que os recursos que passam pelos cofres dos governos municipais são os que trazem maior retorno nas urnas. No entanto, em termos de magnitude do efeito, mesmo as emendas destinadas a prefeituras parecem representar um instrumento secundário na busca por votos.

Os resultados mostram também que as transferências às prefeituras são mais eficazes quando prefeito e deputado são do mesmo partido. Essa é a conclusão derivada da terceira parte do artigo, uma vez que houve uma interação positiva e significativa entre as emendas e o alinhamento partidário de prefeito e parlamentar. A mesma interação não foi positiva entre o alinhamento partidário e as outras formas de emendas, ou seja, o colega de partido na prefeitura apoiaria o deputado apenas quando ele enviasse dinheiro para os cofres do governo municipal.

Ao final do artigo, os resultados da regressão descontínua confirmaram a importância do prefeito correligionário no contexto das emendas, pois o conjunto de deputados ligados a um mesmo partido tende a propor mais emendas para as prefeituras que são dominadas pela sua sigla partidária. Em outras palavras, a decisão de alocação das emendas individuais é bastante sensível ao partido do prefeito.

Em termos teóricos, os achados empíricos contribuem em três pontos para a literatura. Em primeiro lugar, demonstra-se que mesmo nas transferências às prefeituras copartidárias, em que o efeito é maior do que nos demais tipos de emendas, a magnitude do efeito não é suficiente para afirmar que esses recursos sejam fundamentais para a reeleição do deputado. Isso revela que o estímulo ao voto pessoal - característica tão propalada do sistema eleitoral brasileiro - não torna o pork barrel, por si só, um imperativo da sobrevivência política.

Obviamente, em alguns dos modelos empíricos, a vantagem obtida não seria desprezível e poderia auxiliar o deputado a conquistar posições dentro da lista de sua coligação, mas é provável que vários outros objetivos também estejam por trás do uso político das emendas. Uma hipótese que ainda foi pouco testada por trabalhos acadêmicos é a de Samuels (2002), para quem o principal propósito das emendas, do ponto de vista do parlamentar, seria a obtenção de recursos de campanha. O escândalo da máfia dos sanguessugas, em que dinheiro de emendas era desviado para as campanhas eleitorais de parlamentares corruptos, comprova empiricamente que o mecanismo sugerido por Samuels (2002) já foi praticado, ao menos por uma parcela dos parlamentares. Dessa forma, a vantagem eleitoral direta provavelmente é apenas um dos interesses por trás das emendas. A possibilidade de alterar o orçamento público por meio das emendas poderia ser utilizada para vários fins, como obter o apoio de doadores de campanha, buscar cargos no Executivo, ou até mesmo implementar uma política pública valorizada pelo parlamentar. 
Essa miríade de fatores enseja um tema pouco explorado e com elevado potencial para novos estudos.

Em segundo lugar, os resultados desse esforço empírico mostram que a conexão eleitoral entre parlamentar e seus eleitores, promovida por meio das emendas, não é direta. Ao contrário, ela é mediada pelo prefeito, que atua como uma espécie de broker político. Essa intermediação é fundamental para o deputado porque vários parlamentares concorrem por votos nos mesmos locais, e, consequentemente, o eleitor tem dificuldade de identificar o real benfeitor por trás dos benefícios gerados pelas emendas. Para Lancaster (1986), essa é uma situação que deveria inviabilizar a existência de pork barrel, mas, no Brasil, o apoio do prefeito solucionaria esse problema, ainda que parcialmente. Nesse país, a implementação das políticas se dá de forma bastante descentralizada e os municípios são entes federativos autônomos que receberam amplos recursos e responsabilidades após a Constituição Federal de 1988. Dessa forma, o prefeito é um broker natural para os deputados que pretendem aumentar sua influência no nível local. Caso não tenha esse apoio, resta ao deputado enfrentar a difícil tarefa de informar os eleitores de que o benefício criado por suas emendas foi gerado por mérito dele, e não pela ação do governo federal, dos políticos locais ou de outros parlamentares rivais.

Uma terceira contribuição teórica do artigo é mostrar que o partido facilita a articulação entre deputado e prefeito no contexto de aprovação e implementação das emendas. Assim, há mais uma evidência de conexão intrapartidária na arena eleitoral, que se soma a outras levantadas por trabalhos recentes (Avelino, Biderman e Barone, 2012; Barone, 2014). De fato, partidos no Brasil provavelmente não detêm muitas das características que se observam em seus pares nas democracias mais avançadas, mas este artigo é mais um a sugerir que é impreciso simplesmente supô-los fracos no sistema político brasileiro. Nesse país, as organizações partidárias têm sido capazes tanto de mediar as alianças entre políticos de diferentes esferas quanto de possibilitar ações de apoio mútuo na arena eleitoral.

Alexandre Lima Baião - Fundação Getúlio Vargas, Escola de Administração de Empresas de São Paulo. E-mail: <alexandrelimabaiao@gmail.com>.

Cláudio Gonçalves Couto - Fundação Getúlio Vargas, Escola de Administração de Empresas de São Paulo. E-mail: <claudio.couto@fgv.br>.

\section{Referências bibliográficas}

ABRANCHES, S. "Presidencialismo de coalizão: o dilema institucional brasileiro". Dados, vol. $31, \mathrm{n}^{\circ} 1$, p. 3-55, 1988. 
AMES, B. "The reverse coattails effect: local party organization in the 1989 Brazilian presidential election". American Political Science Review, vol. 88, n 1, p. 95-111, 1994.

.Electoral strategy under open-list PR". American Journal of Political Science, vol. 39, $\mathrm{n}^{\circ} 2$, p. 406-33, 1995a.

. Electoral rules, constituency pressures, and pork barrel: bases of voting in the Brazilian Congress". The Journal of Politics, vol. 57, $\mathrm{n}^{\circ} 2$, p. 324-343, 1995b.

The deadlock of democracy in Brazil: interests, identities, and institutions in comparative politics. Ann Arbor: University of Michigan Press, 2001.

AMES, B.; BAKER, A.; ReNNó, L. "The 'quality' of elections in Brazil: policy, performance, pageantry, or pork?". In: POWER, T. J.; KINGSTONE, P. R. (eds.). Democratic Brazil revisited. Pittsburgh: University of Pittsburgh Press, p. 107-133, 2008.

Ames, B.; PEREIRA, C.; RenNó, L. Famintos por pork. Uma análise da demanda e da oferta por políticas localistas e suas implicações para a representação política. In: POWER, T.; ZUCCO JR., C. (orgs.). O Congresso por ele mesmo. Autopercepções da classe política brasileira. Belo Horizonte: Ed. UFMG, 2011.

AMORIM, O.; SANTOS, F. "O segredo ineficiente revisto: o que propõem e o que aprovam os deputados brasileiros". Dados, vol. 46, n 4, p. 661-698, 2003.

Avarte, P.; Barbosa, K.; Fuzitani, E. "Campaign donation and government contracts in Brazilian states". Working Paper 7/2013. Escola de Economia de São Paulo, Fundação Getúlio Vargas, 2013.

Avelino, G.; Biderman, C.; Barone, L. S. "Articulações intrapartidárias e desempenho eleitoral no Brasil". Dados, Rio de Janeiro, vol. 55, n 4, p. 987-1013, 2012.

BARONE, L. S. "Eleições, partidos e política orçamentária no Brasil: explorando os efeitos das eleições locais na política nacional". Tese de Doutorado em Administração Pública e Governo - Eaesp. Fundação Getúlio Vargas, São Paulo, 2014.

BezerRA, M. O. "Políticos, representação política e recursos públicos". Horizontes Antropológicos. Porto Alegre, vol. 7, n 15, p. 181-207, jul. 2001.

BOAS, T. C.; HIDALGO, F. D.; RICHARDSON, N. P. "The spoils of victory: campaign donations and government contracts in Brazil". Journal of Politics, vol. 76, n² 2, p. 415-429, 2014.

BUENO, N. S. "Bypassing your enemy: distributive politics, credit claiming, and non-state organizations in Brazil". Comparative Political Studies, $1^{\circ}$ ago. 2017.

CAIN, B.; FAREJOHN, J. A.; FIORINA, M. The personal vote: constituency service and electoral independence. Cambridge: Harvard University Press, 1987.

CAREY, J. M.; ShugaRT, M. S. "Incentives to cultivate a personal vote: a rank ordering of electoral formulas". Electoral Studies, vol. 14, n 4, p. 417-439, 1995.

CARNeiRo, L. P.; ALmeidA, M. H. T. "Definindo a arena política local: sistemas partidários municipais na federação brasileira". Dados, vol. 51, n², p. 403-432, 2008.

CAUgheY, D.; SeKHON, J. S. "Elections and the regression discontinuity design: lessons from close US House races, 1942-2008". Political Analysis, vol. 19, n 4, p. 385-408, 2011. 
A EFICÁCIA DO PORK BARREL

COMAN, E. E. "Local elites as vehicles for government credit claim". Working paper. Nuffield College, Oxford, 2014.

EGGeRS, A. C., et al. "On the validity of the regression discontinuity design for estimating electoral effects: new evidence from over 40,000 close races". American Journal of Political Science, vol. 59, $\mathrm{n}^{\circ} 1,2015$.

Figueiredo, A.; Limongi, F. "Incentivos eleitorais, partidos e política orçamentária". Dados, vol. 45, nº 2, p. 303-344, 2002.

Políticas orçamentárias no presidencialismo de coalizão. Rio de Janeiro: Editora FGV, 2008.

FirPo, S.; PonCZeK, V.; SANFelice, V. "The relationship between federal budget amendments and local electoral power". Journal of Development Economics, vol. 116, p. 186-198, 2015.

Golden, M. A.; PICCI, L. "Pork-barrel politics in postwar Italy". American Journal of Political Science, vol. 52, n², p. 268-89, 2008.

GRAÇA, L. F. G.; SouZA, C. P. R. "Uso estratégico de eleições alternadas? Efeitos da candidatura para prefeito sobre a votação dos concorrentes ao cargo de deputado federal no Brasil". Opinião Pública, Campinas, vol. 20, no 3, p. 326-345, 2014.

Imbens, G. W.; Kalyanaraman, K. "Optimal bandwidth choice for the regression discontinuity estimator". Review of Economic Studies, vol. 79, n 3, p. 933-959, 2012.

KInZO, M. D.; MARTINS, J. P.; BoRIN, I. "Patrones de competencia electoral en la disputa por la Cámara de Diputados en Brasil (1994-2002)". América Latina Hoy, vol. 38, p. 143-162, 2004.

LANCASTER, T. D. "Electoral structures and pork barrel politics". International Political Science Review, vol. 7, p. 67-81, 1986.

LEMOS, L. B. S. "O Congresso brasileiro e a distribuição de benefícios sociais no período 1988-1994: uma análise distributivista". Dados, vol. 44, n³, p. 561-605, 2001.

LEMOS, L. B. S.; RICCI, P. "Individualismo e partidarismo na lógica parlamentar: o antes e o depois das eleições". In: PowER, T.; Zucco, C. (orgs.). O Congresso por ele mesmo: autopercepções da classe política brasileira. Belo Horizonte: UFMG, 2011.

LIMONGI, F.; FIGUEIREDO, A. "Processo orçamentário e comportamento legislativo: emendas individuais, apoio ao Executivo e programas de governo". Dados, vol. 48, p. 737-776, 2005.

LINZ, J. J. "Presidential or parliamentary democracy: does it make a difference?". In: LINZ, J. J.; VALENZUELA, A. (eds.). The failure of presidential democracy: the case of Latin America. Baltimore: Johns Hopkins University Press, p. 3-87, 1994.

LowI, T. J. "American business, public policy, case-studies, and political theory". World Politics, vol. $16, n^{\circ} 4$, p. 677-715, 1964.

MAINWARING, S. "Democracia presidencialista multipartidária: o caso do Brasil". Lua Nova, vols. 28/29, p. 21-74, 1993a.

"Presidentialism, multipartism, and democracy: the difficult combination". Comparative Political Studies, vol. 26, n² 2, p. 198-228, 1993b.

Sistemas partidários em novas democracias: o caso do Brasil. Porto Alegre/Rio de Janeiro: Mercado Aberto/FGV, 2001. 
MeLLo, L. H. D. P. "A relação entre os poderes Executivo e Legislativo quanto às emendas individuais ao orçamento". Especialização em Orçamento Público. Programa do Instituto Serzedello Corrêa, Tribunal de Contas da União, Brasília, 2012.

MESQUITA, L. "Emendas ao orçamento e conexão eleitoral na Câmara dos Deputados brasileira". 88 p. Dissertação de Mestrado em Ciências Políticas. Universidade de São Paulo, São Paulo, 2008.

Nicolau, J. "O sistema eleitoral de lista aberta no Brasil". Dados, Rio de Janeiro, vol. 49, n 4, p. 689720, 2006.

OLson, M. The logic of collective action. Cambridge, MA: Harvard University Press, 1965.

PENNOCK, J. R. "The pork barrel and majority rule". Journal of Politics, vol. 32, p. 709-716, 1970.

Pereira, C.; Mueller, B. "Comportamento estratégico em presidencialismo de coalizão: as relações entre Executivo e Legislativo na elaboração do orçamento brasileiro". Dados, vol. 45, n 2, p. 265$301,2002$.

. "The cost of governing strategic behavior of the president and legislators in Brazil's budgetary process". Comparative Political Studies, vol. 37, n 7, p. 781-815, 2004.

Pereira, C.; Rennó, L. "Successful reelection strategies in Brazil: the electoral impact of distinct institutional incentives". Electoral Studies, vol. 22, n 3, p. 425-448, 2003.

. "O que é que o reeleito tem? O retorno: o esboço de uma teoria da reeleição no Brasil". Revista de Economia Política, vol. 27, n 4, p. 664-683, 2007.

RiccI, P. "O conteúdo da produção legislativa brasileira: leis nacionais ou políticas paroquiais?". Dados, Rio de Janeiro, vol. 46, n 4, p. 699-734, 2003.

SAMUELS, D. "Pork barreling is not credit claiming or advertising: campaign finance and the sources of personal vote in Brazil". The Journal of Politics, vol. 64, n 3, p. 845-63, 2002.

SANFELICE, V. "Determinantes do voto para deputado federal: relação entre emendas orçamentárias e desempenho eleitoral", 52 f. Tese de Doutorado em Economia. Fundação Getúlio Vargas, São Paulo, 2010.

SILVA, G. P. "Uma discussão acerca das regras eleitorais do sistema político brasileiro e dos incentivos ao comportamento parlamentar". Tese de Doutorado em Administração Pública e Governo, Escola de Administração de Empresas de São Paulo, Fundação Getúlio Vargas, São Paulo, 2009.

. "Uma avaliação empírica da competição eleitoral para a Câmara Federal no Brasil". Opinião Pública, Campinas, vol. 19, n² 2, p. 403-429, 2013.

WeInGAST, B. R. "Reflections on distributive politics and universalism". Political Research Quarterly, vol. 47, n०2, p. 319-327, 1994. 


\section{Apêndice 1}

Formas funcionais utilizadas nas regressões descontínuas

\begin{tabular}{|c|c|c|}
\hline \multicolumn{2}{|r|}{ Especificação } & Forma funcional \\
\hline \multirow{4}{*}{$\stackrel{\circ}{\text { O }}$} & linear $5 \%$ & $\beta_{1} * M+\beta_{2} * T+\beta_{3} T * M$ \\
\hline & linear $2,5 \%$ & $\beta_{1} * M+\beta_{2} * T+\beta_{3} T * M$ \\
\hline & poli $5 \%$ & $\beta_{1} * M+\beta_{2} * M^{2}+\beta_{3} * T+\beta_{4} T * M+\beta_{5} T * M^{2}$ \\
\hline & poli $2,5 \%$ & $\beta_{1} * M+\beta_{2} * M^{2}+\beta_{3} * T+\beta_{4} T * M+\beta_{5} T * M^{2}$ \\
\hline \multirow{12}{*}{ 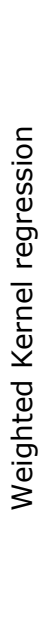 } & local linear IK & $\beta_{1} * M+\beta_{2} * T+\beta_{3} T * M$ \\
\hline & local linear $(10 \%)$ & $\beta_{1} * M+\beta_{2} * T+\beta_{3} T * M$ \\
\hline & local linear $(5 \%)$ & $\beta_{1} * M+\beta_{2} * T+\beta_{3} T * M$ \\
\hline & local linear $(2,5 \%)$ & $\beta_{1} * M+\beta_{2} * T+\beta_{3} T * M$ \\
\hline & poli local grau 2 IK & $\beta_{1} * M+\beta_{2} * M^{2}+\beta_{3} * T+\beta_{4} T * M+\beta_{5} T * M^{2}$ \\
\hline & poli local grau $2(10 \%)$ & $\beta_{1} * M+\beta_{2} * M^{2}+\beta_{3} * T+\beta_{4} T * M+\beta_{5} T * M^{2}$ \\
\hline & poli local grau $2(5 \%)$ & $\beta_{1} * M+\beta_{2} * M^{2}+\beta_{3} * T+\beta_{4} T^{*} M+\beta_{5} T * M^{2}$ \\
\hline & poli local grau $2(2,5 \%)$ & $\beta_{1} * M+\beta_{2} * M^{2}+\beta_{3} * T+\beta_{4} T * M+\beta_{5} T * M^{2}$ \\
\hline & poli local grau 3 IK & $\beta_{1} * M+\beta_{2} * M^{2}+\beta_{3} * M^{3}+\beta_{4} * T+\beta_{5} T^{*} M+\beta_{6} T^{*} M^{2}+\beta_{7} T^{*} M^{3}$ \\
\hline & poli local grau $3(10 \%)$ & $\beta_{1} * M+\beta_{2} * M^{2}+\beta_{3} * M^{3}+\beta_{4} * T+\beta_{5} T * M+\beta_{6} T * M^{2}+\beta_{7} T^{*} M^{3}$ \\
\hline & poli local grau $3(5 \%)$ & $\beta_{1} * M+\beta_{2} * M^{2}+\beta_{3} * M^{3}+\beta_{4} * T+\beta_{5} T * M+\beta_{6} T * M^{2}+\beta_{7} T * M^{3}$ \\
\hline & poli local grau $3(2,5 \%)$ & $\beta_{1} * M+\beta_{2} * M^{2}+\beta_{3} * M^{3}+\beta_{4} * T+\beta_{5} T^{*} M+\beta_{6} T^{*} M^{2}+\beta_{7} T^{*} M^{3}$ \\
\hline
\end{tabular}

Fonte: Elaboração própria. 
Apêndice 2

Impacto da vitória do partido nas variáveis defasadas

\begin{tabular}{|c|c|c|c|c|c|c|c|c|c|c|c|}
\hline \multirow{2}{*}{\multicolumn{2}{|c|}{ Esp }} & \multicolumn{2}{|c|}{$\begin{array}{c}\text { Emenda40 } \\
\text { defasada } \\
\text { Empenhado }\end{array}$} & \multicolumn{2}{|c|}{$\begin{array}{l}\text { Emenda40 } \\
\text { defasada } \\
\text { Acréscimo }\end{array}$} & \multicolumn{2}{|c|}{$\begin{array}{c}\text { Emenda40 } \\
\text { defasada } \\
\text { Empenhado } \\
\text { por eleitor }\end{array}$} & \multicolumn{2}{|c|}{$\begin{array}{c}\text { Emenda40 } \\
\text { defasada } \\
\text { Acréscimo por } \\
\text { eleitor }\end{array}$} & \multicolumn{2}{|c|}{$\begin{array}{l}\text { Total de votos } \\
\text { do partido na } \\
\text { eleição } \\
\text { nacional } \\
\text { anterior }\end{array}$} \\
\hline & & Coef. & $\begin{array}{l}\text { N. de } \\
\text { obs. }\end{array}$ & Coef. & $\begin{array}{l}\text { N. de } \\
\text { obs. }\end{array}$ & Coef. & $\begin{array}{l}\text { N. de } \\
\text { obs. }\end{array}$ & Coef. & $\begin{array}{l}\text { N. de } \\
\text { obs. }\end{array}$ & Coef. & $\begin{array}{l}\text { N. de } \\
\text { obs. }\end{array}$ \\
\hline \multirow{4}{*}{$\begin{array}{l}\stackrel{O}{ } \\
\Sigma\end{array}$} & linear 5\% & 0,21 & 2669 & 0,52 & 2669 & 2,27 & 2669 & 3,38 & 2669 & 176,42 & 5576 \\
\hline & linear $2,5 \%$ & $-0,83$ & 1305 & $-1,90$ & 2669 & $-1,32$ & 2669 & $-3,22$ & 2669 & 110,96 & 2756 \\
\hline & poli $5 \%$ & 0,94 & 2669 & $-2,27$ & 1305 & $-0,92$ & 1305 & $-3,21$ & 1305 & 185,76 & 5576 \\
\hline & poli $2,5 \%$ & $-1,62$ & 1305 & $-2,15$ & 2669 & $-5,16$ & 2669 & $-7,23$ & 2669 & 81,24 & 2756 \\
\hline \multirow{12}{*}{ 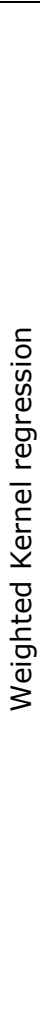 } & $\begin{array}{l}\text { local linear } \\
\text { IK }\end{array}$ & 2,27 & 4684 & 2,64 & 4521 & 2,58 & 4936 & 3,88 & 4669 & 79,08 & 14210 \\
\hline & $\begin{array}{l}\text { local linear } \\
(10 \%)\end{array}$ & 2,76 & 4987 & 4,01 & 4987 & 2,58 & 4987 & 3,73 & 4987 & 108,57 & 10330 \\
\hline & $\begin{array}{l}\text { local linear } \\
(5 \%)\end{array}$ & 0,51 & 2669 & $-0,60$ & 2669 & 0,97 & 2669 & 0,69 & 2669 & 180,23 & 5576 \\
\hline & $\begin{array}{l}\text { local linear } \\
(2,5 \%)\end{array}$ & $-1,14$ & 1305 & $-2,00$ & 1305 & $-2,74$ & 1305 & $-4,69$ & 1305 & 99,45 & 2756 \\
\hline & \begin{tabular}{|l|} 
poli local \\
grau 2 IK \\
\end{tabular} & $-0,91$ & 5117 & $-2,17$ & 4985 & 2,81 & 6546 & 3,79 & 6053 & 145 & 14994 \\
\hline & $\begin{array}{l}\text { poli local } \\
\text { grau } 2 \\
(10 \%) \\
\end{array}$ & $-0,91$ & 4987 & $-2,17$ & 4987 & 1,34 & 4987 & 1,80 & 4987 & 156,36 & 10330 \\
\hline & \begin{tabular}{|l|} 
poli local \\
grau 2 \\
$(5 \%)$
\end{tabular} & $-0,76$ & 2669 & $-2,16$ & 2669 & $-2,51$ & 2669 & $-4,87$ & 2669 & 137,63 & 5576 \\
\hline & $\begin{array}{l}\text { poli local } \\
\text { grau } 2 \\
(2,5 \%) \\
\end{array}$ & $-0,96$ & 1305 & $-3,13$ & 1305 & $-4,44$ & 1305 & $-7,49$ & 1305 & $-18,47$ & 2756 \\
\hline & \begin{tabular}{|l|} 
poli local \\
grau 3 IK
\end{tabular} & $-0,91$ & 7013 & $-5,19$ & 6074 & 0,03 & 6159 & $-1,94$ & 5669 & 186,2 & 16020 \\
\hline & $\begin{array}{l}\text { poli local } \\
\text { grau } 3 \\
(10 \%)\end{array}$ & $-0,48$ & 4987 & $-2,51$ & 4987 & $-1,88$ & 4987 & $-4,34$ & 4987 & 196,42 & 10330 \\
\hline & $\begin{array}{l}\text { poli local } \\
\text { grau } 3 \\
(5 \%)\end{array}$ & $-2,94$ & 2669 & $-3,09$ & 2669 & $-5,83$ & 2669 & $-8,48$ & 2669 & 2,23 & 5576 \\
\hline & $\begin{array}{l}\text { poli local } \\
\text { grau } 3 \\
(2,5 \%)\end{array}$ & $-1,95$ & 1305 & $-7,56$ & 1305 & $-7,05$ & 1305 & $-12,63$ & 1305 & 117,39 & 2756 \\
\hline
\end{tabular}

Fonte: Elaboração própria.

Os percentuais da segunda coluna se referem à "largura da banda" (bandwidth), que pode ter sido atribuída manualmente ou pelo método IK.

O peso das regressões ponderadas utilizou uma função Kernel triangular.

Informações pormenorizadas sobre as formas funcionais aplicadas são fornecidas no Apêndice 1. 


\section{Resumo}

A eficácia do pork barrel: a importância de emendas orçamentárias e prefeitos aliados na eleição de deputados

Há pouco consenso, nos estudos empíricos, sobre o efeito eleitoral das emendas orçamentárias individuais. O artigo retoma essa questão, utilizando regressões com dados em painel para estudar como as emendas de um deputado afetam seu desempenho na disputa pela reeleição. Ademais, aplica-se uma regressão descontínua para estudar como o partido do prefeito afeta a proposição e a execução das emendas orçamentárias. Os resultados mostram que apenas emendas executadas como transferências a prefeituras geram votos, principalmente quando o prefeito é correligionário do parlamentar. Além disso, um volume maior de emendas é proposto e executado nas prefeituras correligionárias.

Palavras-chave: emendas orçamentárias; pork barrel politics; conexão eleitoral; eleições nacionais; prefeitos

\section{Abstract}

Pork barrel efficacy: the importance of budgetary amendments and allied mayors in the election of deputies

There is little consensus among empirical studies regarding the electoral effect of individual budget amendments. The present article addresses this question by using regressions with panel data to study how a deputy's amendments affect his performance in the race for re-election. In addition, a regression discontinuity is estimated to assess how the mayor's party affects the proposition and execution of the budget amendments. The results show that only amendments made as transfers to mayoral administrations generate votes, especially when the mayor belongs to the party of the legislator. In addition, a larger volume of amendments is proposed and implemented in the municipalities.

Keywords: budget amendments; pork barrel politics; electoral connection; national elections; mayors

\section{Resumen}

Eficacia del pork barrel: la importancia de enmiendas presupuestarias y alcaldes aliados en la elección de diputados

Es común en Brasil el argumento de que los diputados federales buscan reputación y reelección enviando fondos a sus fortalezas políticas a través de enmiendas presupuestarias. Sin embargo, los estudios empíricos no han identificado un efecto relevante de estas enmiendas en las elecciones. Este artículo aborda esta cuestión con datos más detallados y métodos más precisos para verificar la eficacia electoral de las enmiendas presupuestarias. Además, este estudio explora el papel que juegan los intendentes en la conversión de las enmiendas en votos. Los resultados muestran que sólo las enmiendas presupuestarias enviadas como transferencias a los gobiernos municipales pueden generar votos, principalmente cuando el alcalde y el diputado son miembros del mismo partido.

Palabras clave: enmiendas presupuestarias; pork barrel politics; sistema electoral; conexión electoral; alcaldes 


\section{Résumé}

L'efficacité du pork barrel: l'importance des amendements budgétaires et des maires alliés dans l'élection des députés

L'argument selon lequel les députés fédéraux cherchent à se faire une réputation et à se faire réélire en envoyant des fonds à leurs bastions politiques par des amendements budgétaires est commun au Brésil. Cependant, les études empiriques n'ont pas identifié d'effet pertinent de ces amendements sur les élections. Cet article reprend cette question en utilisant des données plus détaillées et des méthodes plus précises pour vérifier l'efficacité électorale des modifications budgétaires. En outre, cette étude explore le rôle que les maires jouent dans la conversion des amendements en votes. Les résultats montrent que seules les modifications budgétaires envoyées en transferts aux administrations municipales peuvent générer des votes, principalement lorsque le maire et le député sont membres du même partis.

Mots-clés: amendements budgétaires; pork barrel politics; système électoral; connexion électoral; maires

Artigo submetido à publicação em 15 de janeiro de 2017.

Versão final aprovada em 8 de novembro de 2017. 